\title{
Nectin-2 Expression in Testicular Cells Is Controlled via the Functional Cooperation Between Transcription Factors of the Sp1, CREB, and AP-1 Families
}

\author{
WING-YEE LUI, KIT-LING SZE, AND WILL M. LEE* \\ Department of Zoology, The University of Hong Kong, Pokfulam, Hong Kong
}

\begin{abstract}
Nectin-2, a major protein component of the adherens junctions (AJs), is found between Sertoli cells and germ cells in the seminiferous epithelium. Recent studies have shown that the expression of nectin-2 gene in testis is crucial to maintain normal spermatogenesis since male knockout mice lacking nectin-2 gene are sterile and possess morphologically abnormal spermatozoa. However, the molecular mechanisms governing its basal transcription remain poorly understood. By the use of Sertoli and germ cell-lines (TM4 and GC-2spd(ts) cells, respectively) in transient transfection studies, we showed that the minimal mouse nectin-2 promoter was located between nucleotides -316 and -211 (relative to the translation start site). Two putative Sp1 motifs and one each of the CRE, AP1, and AP2 motifs were identified within this region. Mutational studies showed that these two Sp1 motifs cooperated synergistically with the CRE motif, but not the AP1 and AP2 motifs, to regulate nectin-2 gene transcription in both TM4 and GC-2spd(ts) cells. By EMSAs, we found that an AP-1 consensus sequence was able to inhibit DNA-protein complex formation with the CRE motif, suggesting an interaction between the AP-1 transcription factor (c-Jun) and CREB within the CRE motif. Overexpressions of CREB and c-Jun, but not c-Fos, also significantly increased the promoter activity, which suggests that CREB and c-Jun are the crucial transcription factors involved in regulating nectin-2 gene transcription. Chromatin immunoprecipitation assay has shown that, in vivo, CREB, c-Jun, and Sp1 family proteins are bound to the mouse nectin-2 promoter. Analysis of the staged tubules has confirmed that the cyclic expressions of CREB and nectin-2 coincide with the event of adherens junction restructuring between Sertoli cells and germ cells. The cross-talk between CREB, c-Jun, and Sp1 family protein is believed to be a major transcription machinery to drive nectin-2 expression in Sertoli cells. J. Cell. Physiol. 9999: 1-14, 2005. (c) 2005 Wiley-Liss, Inc.
\end{abstract}

Throughout spermatogenesis, germ cells must migrate from the basal to the adluminal compartment of the seminiferous epithelium, which associates with extensive restructuring of the actin-based cell-cell adherens junctions (AJs). Ectoplasmic specializations (ES) are specialized actin-based cell-cell AJs unique to the testis. They can be found between Sertoli cells at the basal region of the seminiferous epithelium (basal ES) or at the apical region of the seminiferous epithelium in which developing and mature spermatids attach onto Sertoli cells (apical ES) (for reviews, see Russell, 1977b, 1980). The turnover of basal ES allows the movement of spermatocytes across the seminiferous epithelium (Russell, 1977a), whereas the release of mature spermatids (spermatozoa) from the seminiferous epithelium at spermiation is accomplished by the disassembly of apical ES (Vogl et al., 2000). Nectins are found on both Sertoli cells and spermatids and function as interlocking proteins. They have been evident to involve in cell adhesion between Sertoli cells and spermatids at the apical ES (Ozaki-Kuroda et al., 2002).

Nectin is a $\mathrm{Ca}^{2+}$-independent cell adhesion molecule that belongs to the immunoglobulin-like superfamily (Morrison and Racaniello, 1992; Takahashi ${ }^{\mathrm{Q} 1}$ et al., 1999). Unlike classic cadherins, nectins form not only homotypic AJs, but also heterotypic AJs (Kemler, 1992; Satoh-Horikawa et al., 2000). For instance, nectin-1and nectin-3 heterotypic interactions are found at the preand post-synaptic regions of synapses (Satoh-Horikawa et al., 2000; Mizoguchi et al., 2002). Among the nectin family members, nectin-3 is most abundantly expressed and nectin-2 modestly expressed in the testis (Reymond et al., 2000; Satoh-Horikawa et al., 2000). Northern blot analysis revealed that all nectin-2 splicing variants were detected in Sertoli cells and germ cells at all ages, whilst all nectin-3 splicing variants were found mainly in spermatids of the germ cell fraction (Ozaki-Kuroda et al., 2002). Studies from nectin- $2^{-/-}$knockout mice showed that all male mice were infertile and produced morphological abnormal spermatozoa. For instance, the heads of spermatids showed irregular shapes with distorted nucleus. Mitochondria were present in the spermatid head and unable to pack tightly to form a helical sheath (Bouchard et al., 2000; Mueller et al., 2003).

Immunofluoroscent analyses have showed that nectin-2 and nectin-3 colocalize with F-actin at Sertolispermatid junctions (apical ES). The appearance and disappearance of the nectin staining at apical ES were coincident to the assembly and disassembly of Sertolispermatid junctions, suggesting that actin-based heterotypic interaction between nectin-2 and nectin-3 might exist at apical ES in the seminiferous epithelium (Ozaki-Kuroda et al., 2002). Using transplantation techniques, nectin-2 $2^{-/-}$spermatogonia when transplantated into nectin $-2^{+/-}$testes were able to differentiate into normal spermatids, while nectin- $2^{+/-}$spermatogonia transplantated into nectin- $2^{-1-}$ testes were not. These studies have indicated that nectin-2 in Sertoli cells contributes to the proper formation of heterotypic interaction

Contract grant sponsor: Hong Kong Research Grant Council; Contract grant numbers: HKU 7194/01M, HKU 7413/04M, HKU7536/05M; Contract grant sponsor: The University of Hong Kong.

*Correspondence to: Will M. Lee, Department of Zoology, The University of Hong Kong, Pokfulam Road, Hong Kong.

E-mail: hrszlwm@hku.hk

Received 28 June 2005; Accepted 19 September 2005

Published online in Wiley InterScience

(www.interscience.wiley.com.), 00 Month 2005.

DOI: $10.1002 /$ jcp. 20545 
between nectin-2 in Sertoli cells and nectin-3 in spermatids at Sertoli-spermatid junctions (OzakiKuroda et al., 2002).

Not only proper formation of basal ES is crucial for germ cell differentiation, but also the timely disassembly of the apical ES is required to allow the release of mature spermatids. The disassembly and reassembly of ES appear to be controlled primarily by regulating the nectin-2 and nectin-3 genes at the transcriptional level. To address this issue, two nectin-2-expressing testicular cell lines, TM4 and GC-2spd(ts), were used to identify and characterize the transcriptional machinery important for the nectin-2 gene expression in Sertoli cells and germ cells. In the present study, we have demonstrated that the regulation of nectin- 2 gene expression requires functional cooperation between multiple transcription factors.

\section{EXPERIMENTS \\ Cells and cell culture}

Mouse TM4 and GC-2spd(ts) were obtained from American Type Culture Collection (Manassas, VA). Cells were maintained in DMEM (Invitrogen, Calisbad, CA) containing $10 \%$ FBS. Cultures were maintained at $37^{\circ} \mathrm{C}$ in humidified atmosphere with $5 \% \mathrm{CO}_{2}$ in air.

\section{Preparation of nectin-2 promoter-luciferase constructs and site-directed mutagenesis}

The 5'-flanking region of the nectin- 2 gene was generated using the mouse GenomeWalker Kit (Clontech, Palo Alto, CA) and primer \#850 (Table 1). Various
5 -deleted regions generated by PCR were cloned into the promoterless pGL-3 Basic vector (Promega Corp., Madison, WI). Mutant plasmids were generated by a three-step PCR mutagenesis (Wong and Lee, 2002) using mutagenic primers (Table 1). All plasmids were prepared by Plasmid Midi Kits (Qiagen, Chatsworth, CA) and confirmed by sequencing analysis.

\section{Preparation of CREB-siRNA construct and its mutant}

Oligonucleotides containing the CREB-siRNA or mut CREB-siRNA sequences were annealed respectively. Annealed oligonucleotides and pSilencer 1.0-U6 siRNA expression vector (Ambion, Austin, TX) were digested by ApaI and EcoRI for subsequent cloning.

\section{Transient transfection and reporter gene assay}

$1 \times 10^{5}$ cells were seeded onto a 6 -well culture plate a day before transfection. Luciferase constructs $(1 \mu \mathrm{g})$ were co-transfected with pSV- $\beta$-gal $(0.5 \mu \mathrm{g})$ using Lipofectamine reagent (Invitrogen) in serum-free media. Five hours after transfection, 20\% FBS was added and cells were incubated overnight. Lipofectamine was replaced and cells were cultured for another $24 \mathrm{~h}$ before harvest. Luminescence was measured by a Lumat LB 9507 luminometer (EG\&G, Berthold, Germany). $\beta$-Galactosidase activity was measured by a $\beta$-galactosidase enzyme assay system (Promega Corp.) and used to normalize transfection efficiency. Promoter activity was calculated as luciferase activity/ $\beta$-galactosidase activity.

TABLE 1. Nucleotide sequence of primers used in plasmid construction, site-directed mutagenesis, and EMSA

\begin{tabular}{|c|c|c|c|c|}
\hline Primer name & Location & Orientation & Sequence $\left(5^{\prime} \rightarrow 3^{\prime}\right)$ & Purpose \\
\hline 847 & $28 / 47$ & $\mathrm{~S}$ & $5^{\prime}$ TCC AGA TTG TCA CCG ACG CT $3^{\prime}$ & Amplification of cDNA \\
\hline 848 & $549 / 569$ & AS & $5^{\prime}$ GAT GAG ATC CAG GTG ATT CGG $3^{\prime}$ & Amplification of cDNA \\
\hline 850 GSP & $33 / 58$ & AS & $5^{\prime}$ GCA ACA ACG GCA GCG TCG GTG ACA AT $3^{\prime}$ & GenomeWalk \\
\hline 861 & $-90 /-106$ & $\mathrm{~S}$ & $5^{\prime}$ ACG CGT GGA GCC GGA CAC TTC A $3^{\prime}$ & Deletion \\
\hline 862 & $-196 /-211$ & $\mathrm{~S}$ & $5^{\prime}$ ACG CGT CTG GAG CTA AGC GAG G $3^{\prime}$ & Deletion \\
\hline 895 & $-299 /-316$ & $\mathrm{~S}$ & $5^{\prime}$ GGA CGC GTG ATG GGC GGG $3^{\prime}$ & Deletion \\
\hline 863 & $-381 /-399$ & $\mathrm{~S}$ & $5^{\prime}$ ACG CGT GGC TCC ATG TCG AGT G $3^{\prime}$ & Deletion \\
\hline 864 & $-510 /-528$ & $\mathrm{~S}$ & $5^{\prime}$ ACG CGT GGT CTG GGC GAG AAG $3^{\prime}$ & Deletion \\
\hline 865 & $-646 /-662$ & $\mathrm{~S}$ & $5^{\prime}$ ACG CGT GAC CCC GAC CTA CCA $3^{\prime}$ & Deletion \\
\hline 879 & $-813 /-830$ & $\mathrm{~S}$ & $5^{\prime}$ ACG CGT GAC ATA GGC ACA TGG ACA $3^{\prime}$ & Deletion \\
\hline 880 & $-928 /-946$ & $\mathrm{~S}$ & $5^{\prime}$ ACG CGT CTG GGC TGG TAT TAA GAG T $3^{\prime}$ & Deletion \\
\hline 894 & $20 / 34$ & AS & $5^{\prime}$ GAA GAT CTG GAC GGC GGG A $3^{\prime}$ & \\
\hline 1099 & $1322 / 1346$ & $\mathrm{~S}$ & $5^{\prime}$ AGA TGC CTC GGT ATC ACG AGC TGC C $3^{\prime}$ & ChIP assay \\
\hline 1100 & $1566 / 1592$ & AS & $5^{\prime}$ CAC ACA TAC ATG GCC CGT GAC ACA AA $3^{\prime}$ & ChIP assay \\
\hline MPB & & $\mathrm{S}$ & $\begin{array}{l}5^{\prime} \text { GGA GTA CTA ACC CTG GCC TAG CAA AAT AGG } \\
\text { CTG TCC C } 3^{\prime}\end{array}$ & Mutagenic universal primer \\
\hline MPC & & AS & $5^{\prime}$ CTT TAT GTT TTT GGC GTC TTC CA $3^{\prime}$ & Mutagenic universal primer \\
\hline MPD & & $\mathrm{S}$ & $5^{\prime}$ GGA GTA CTA ACC CTG GC $3^{\prime}$ & Mutagenic universal primer \\
\hline 901 CRE-BP & $-216 /-241$ & $\mathrm{~S}$ & $5^{\prime}$ CCG GAC TCA $a$ G $t$ CGT gAC AGG CCC CG $3^{\prime}$ & Site-directed mutagenesis \\
\hline 902 pSP-1 & $-227 /-254$ & AS & $5^{\prime}$ ACG TCA CAG GCC C $t$ G $a a C$ CTC TTC GCC A $3^{\prime}$ & Site-directed mutagenesis \\
\hline $920 \mathrm{dSP} 1$ & $-288 /-315$ & AS & $5^{\prime}$ AGG GCT AAG ACC C $t$ G $a a$ C ATC ACG CGT C 3' & Site-directed mutagenesis \\
\hline 931 CREB-dSP1 & $-217 /-251$ & AS & $\begin{array}{l}\text { 5’ CGG ACT CA } a \text { GtC GTg ACA GGC CC } t \text { Gaa CCT } \\
\text { CTT CG } 3^{\prime}\end{array}$ & Site-directed mutagenesis \\
\hline 904 GS-CREB-S & $-217 /-237$ & AS & $5^{\prime}$ GCC TGT GAC GTC ATG AGT CCG $3^{\prime}$ & Gel-shift \\
\hline 906 GS-CREB*-S & $-231 /-252$ & $\mathrm{~S}$ & $5^{\prime}$ GCC TGT $c$ AC GaC $t$ TG AGT CCG $3^{\prime}$ & Gel-shift \\
\hline 908 GS-pSP1-S & $-231 /-252$ & $\mathrm{~S}$ & $5^{\prime}$ GCG AAG AGG GGC GGG GCC TGT G $3^{\prime}$ & Gel-shift \\
\hline 910 GS-pSP1*-S & $-231 /-252$ & $\mathrm{~S}$ & $5^{\prime}$ GCG AAG AGG $t t$ C $a$ GG GCC TGT G $3^{\prime}$ & Gel-shift \\
\hline 912 GS-dSP1-S & $-291 /-313$ & $\mathrm{~S}$ & $5^{\prime}$ CGC GGG ATG GGC GGG GTC TTA GC $3^{\prime}$ & Gel-shift \\
\hline 914 GS-dSP1*-S & $-291 /-313$ & $\mathrm{~S}$ & $5^{\prime}$ CGC GGG ATG $t t$ C $a$ GG GTC TTA GC $3^{\prime}$ & Gel-shift \\
\hline 1037 GS-CREBmAP1-S & $-217 /-237$ & $\mathrm{~S}$ & $5^{\prime}$ GCC TGT GAC GTC AT $t c$ GT $t$ CG $3^{\prime}$ & Gel-shift \\
\hline 1059 specific CREB-siRNA & & $\mathrm{S}$ & $\begin{array}{l}5^{\prime} \text { ACG AAG GGA AAT CCT TTC ATT CAA GAG ATG } \\
\text { AAA GGA TTT CCC TTC GTT TTT TT }\end{array}$ & \\
\hline 1060 specific CREB-siRNA & & AS & $\begin{array}{l}5^{\prime} \text { AAT TAA AAA AAC GAA GGG AAA TCC TTT CAT } \\
\text { CTC TTG AAT GAA AGG ATT TCC CTT CGT GGC C }\end{array}$ & \\
\hline 1061 mCREB-siRNA & & $\mathrm{S}$ & $\begin{array}{l}5^{\prime} \text { ACG AAG Gct AAT CCT TTC ATT CAA GAG ATG } \\
\text { AAA GGA TTa gCC TTC GTT TTT TT }\end{array}$ & \\
\hline 1062 mCREB-siRNA & & AS & $\begin{array}{l}5^{\prime} \text { AAT TAA AAA AAC GAA GGc } t \text { AA TCC TTT CAT } \\
\text { CTC TTG AAT GAA AGG ATT agC CTT CGT GGC C }\end{array}$ & \\
\hline
\end{tabular}




\section{Electrophoretic mobility shift assay (EMSA)}

Oligonucleotides containing the putative $\mathrm{Sp} 1$ [d(distal) Sp1, p(proximal)Sp1] and CRE and the corresponding mutated oligonucleotides were annealed to form doublestranded DNA (Table 1). Probes were end-labeled with $\left[\alpha^{-}{ }^{32} \mathrm{P}\right]$-ATP and separated from unincorporated nucleotides via the Microspin G-25 columns (Amersham Biosciences, Piscataway, NJ). Nuclear extracts were prepared as described (Wong and Lee, 2002). EMSA was performed in a $20 \mu \mathrm{l}$ reaction mixture containing $20 \mathrm{mM}$ HEPES (pH 7.5), $50 \mathrm{mM} \mathrm{NaCl}, 1.5 \mathrm{mM} \mathrm{MgCl} 2,1 \mathrm{mM}$ DTT, $1 \mathrm{mM}$ EDTA, $10 \%$ glycerol, $1 \mu \mathrm{g}$ poly (dI:dC), $50 \mathrm{fmol}$ radiolabeled probe $(50,000 \mathrm{cpm})$, and nuclear extract. For competitive assay, competitor oligonucleotides were added simultaneously with the radiolabeled probes. For supershift assay, nuclear extracts were preincubated with the antibodies $(1-2.5 \mu \mathrm{g})$ for $30 \mathrm{~min}$. Anti-Sp1, anti-Sp3, and anti-CREB antibodies were from Santa Cruz Biotechnology (Santa Cruz, CA). The binding reaction was carried out at room temperature for $15 \mathrm{~min}$ and the reaction products were separated on a 6\% polyacrylamide gel. The gels were dried and then exposed to X-ray film (Eastman Kodak Co., Rochester, NY) at $-70^{\circ} \mathrm{C}$ overnight.

\section{Chromatin immunoprecipitation (ChIP) assay}

The ChIP assay was performed as described (Baek et al., 2001). Macromolecules in exponentially growing cells were cross-linked with $1 \%$ formaldehyde. Cells were resuspended in lysis buffer (1\% SDS, $10 \mathrm{mM}$ EDTA, $50 \mathrm{mM}$ Tris, $\mathrm{pH}$ 8.1, $1 \mathrm{mM}$ PMSF, and protease inhibitors) and sonicated by Sonifier 450 (Branson, Danbury, CT). Lysates were cleared by centrifugation and diluted in IP buffer $(0.1 \%$ SDS, $1 \%$ Triton X-100, $0.1 \%$ sodium deoxychloate, $140 \mathrm{mM} \mathrm{NaCl}, 1 \mathrm{mM}$ PMSF, and protease inhibitors). Antibody $(10 \mu \mathrm{g})$ and $20 \mu \mathrm{l}$ protein $\mathrm{A} / \mathrm{G}$ agarose were added to the precleared chromatin solution for incubation overnight at $4^{\circ} \mathrm{C}$. Beads were washed with washing buffer $(0.1 \%$ Triton X200, $20 \mathrm{mM}$ Tris, $\mathrm{pH}$ 8.0, $150 \mathrm{mM} \mathrm{NaCl}, 2 \mathrm{mM}$ EDTA) and eluted in the elution buffer (1\% SDS and $0.1 \mathrm{M}$ $\mathrm{NaHCO}_{3}$ ). The solution was heated at $65^{\circ} \mathrm{C}$ for $4 \mathrm{~h}$ followed by proteinase $\mathrm{K}$ digestion and phenol/chloroform extraction. The extracted DNA was used for PCR using the primer pairs \#895/\#894 and \#1099/\#1100, respectively.

\section{Microdissection of staged tubules by transillumination microscopy}

Separation of staged tubules was performed under a stereomicroscope. The wave of the seminiferous tubules was determined as earlier described (Parvinen and Vanha-Perttula, 1972) and tubules were dissected into two groups as follows: Group 1 containing dark zone and dark spot zone (stages II-VIII) and Group 2 containing pale zone and weak spot zone (stages IX-I). Isolated staged tubules were used for RNA extraction.

\section{RT-PCR}

Total RNA was isolated from cells by TRIZOL reagent (Invitrogen). RT-PCR was performed essentially as previously described (Lui and Lee, 2005). RT product $(2 \mu \mathrm{l})$ was used as template for RT-PCR with a pair of nectin-2 and S16 primers (Table 1). Co-amplifications of nectin-2 and S16 were in their linear phases. The authenticity of the PCR product was confirmed by nucleotide sequencing.

\section{Data analysis}

For all transfection assays, data were shown as mean \pm SD of duplicate assays in three independent experiments. For EMSAs, all studies were repeated three times and consistent results were obtained. Data from mutation study were analyzed by one-way ANOVA, followed by Tukey's multiple comparison tests using the computer software PRISM (GraphPad Software, Inc., San Diego, CA).

\section{RESULTS \\ Expression of mouse nectin-2 in testicular cell lines \\ RT-PCR was performed to study the expression of nectin-2 at the mRNA levels in two testicular cell lines, TM4 (Sertoli cell line) and GC-2spd(ts) (germ cell line). A 542-bp PCR fragment was obtained in both cell lines with a higher mRNA level in GC-2spd(ts) cells (Fig. 1A). The authenticity of the PCR products was confirmed by DNA base sequencing. \\ Mapping of the mouse nectin-2 promoter in TM4 and GC-2spd(ts) cells}

Although the transplantation study demonstrated that nectin-2 gene in germ cells is not responsible for the Sertoli-germ cell adhesion, it is possible that nectin-2 exerts a yet-to-identified function other than cell adhesion in the seminiferous epithelium since germ cells express a relatively high level of nectin- 2 in the testis (Ozaki-Kuroda et al., 2002).

To locate the active promoter regions of the nectin-2 gene, progressive $5^{\prime}$-deletion mutants were constructed and analyzed in TM4 and GC-2spd(ts) cells (Fig. 1B). Results of transient transfection study revealed that both TM4 and GC-2spd(ts) cells show similar promoter activity profiles. Deletion of the nectin-2 $5^{\prime}$-flanking sequence from nt -946 to -662 had no apparent effect on the promoter activity in both cell lines. Further deletion of 134-bp from $\mathrm{p}(-662 /+34)$ Luc increased the promoter activities in both cell lines. Also, $5^{\prime}$-deletion of a 84-bp fragment from $\mathrm{p}(-399 /+34)$ Luc increased the promoter activity by $59.9 \%$ and $53.3 \%$ in TM4 and GC-2spd(ts) cells, respectively (Fig. 1B), suggesting that negative regulatory elements might locate between $\mathrm{nt}-399$ and -316 .

The maximal promoter activities [13.6-fold for TM4 cells and 12.8-fold for GC-2spd(ts) cells] were obtained when $5^{\prime}$-sequence was deleted to $\mathrm{nt}-316$. However, further removal of sequence to nt -211 completely abolished the promoter activity. These results indicated that the core promoter of nectin-2 gene is located within the region between $n t-316$ and -211 in both cell lines (Fig. 1B).

Mutational analysis of putative CRE, Sp1, AP-1, and AP-2 motifs within the core promoter region

Two putative Sp1 binding sites, namely distal Sp1 (dSp1) (5'-TGGGCGGGGT-3', located from nt -306 to -297 , with $94.5 \%$ homology to the $\mathrm{Sp} 1$ consensus motif) and proximal Sp1 (pSp1) (5'-GGGGCGGGGC-3', located from nt -245 to -235 , with $94.5 \%$ homology to $\mathrm{Sp} 1$ consensus motif), and one each of the motifs including CRE, AP-1, and AP-2 (5'-TGACGTCA-3' , located from nt -232 to -225 , with $100 \%$ homology to CRE consensus motif; $5^{\prime}$-TGAGTCC-3', located from nt -224 to -218 , with $85.3 \%$ homology to AP-1 consensus motif; 5'GGCCCG-3', located from nt -217 to -212 , with $89 \%$ homology to AP-2 consensus motif) were identified within the core promoter region (Fig. 2A). To examine 
A

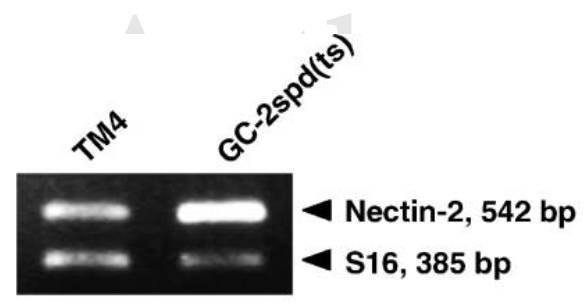

\section{B}

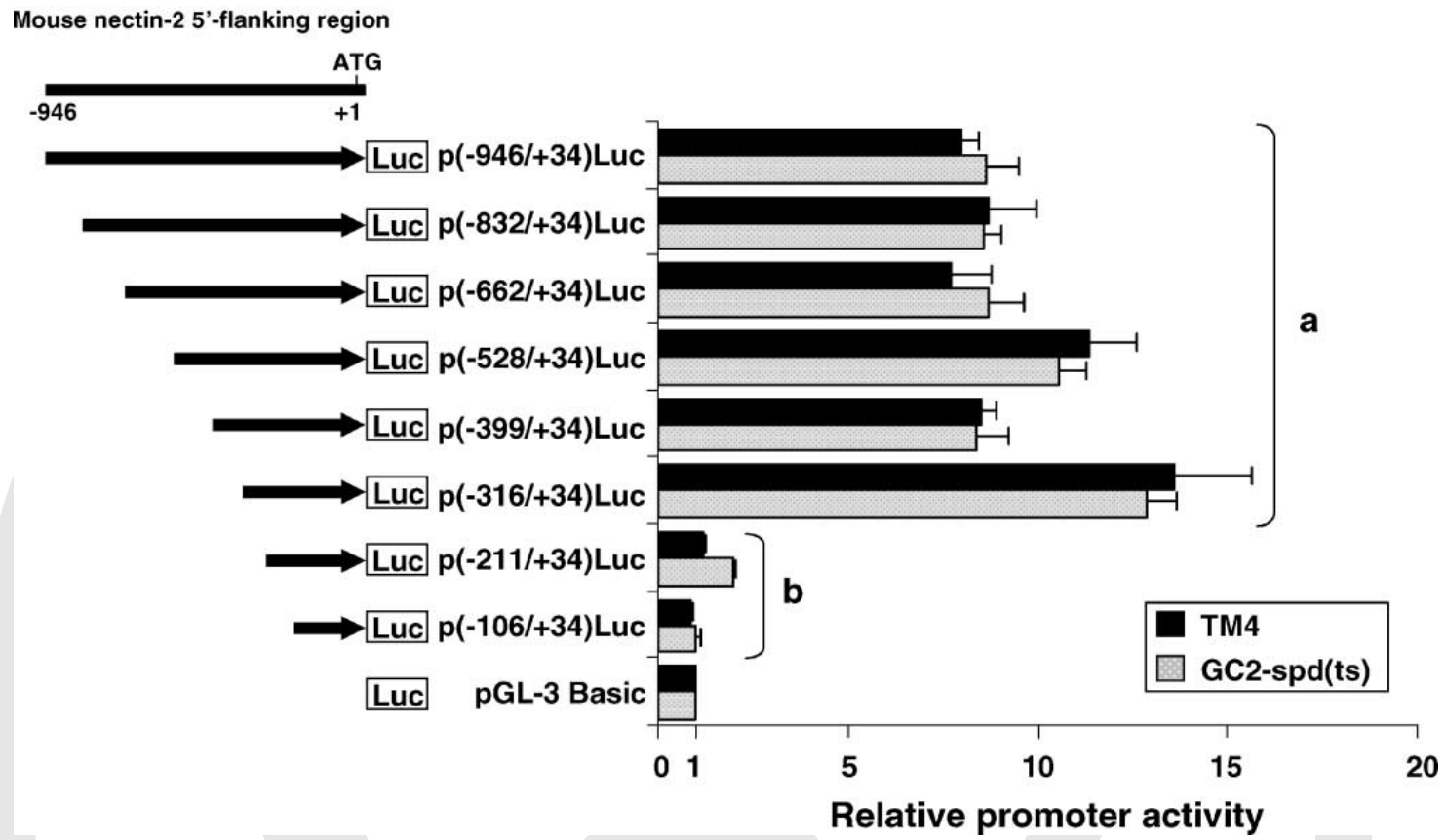

Fig. 1. A-B: Expression of mouse nectin-2 mRNA in TM4 and GC$2 \mathrm{spd}(\mathrm{ts})$ cells and progressive $5^{\prime}$-deletion analysis of nectin-2 promoter. A: Co-amplification of nectin-2 and S16 cDNAs from TM4 and GC2 spd(ts) cells using a pair of primers specific to nectin-2 and $S 16$ genes. The authenticity of the PCR product was confirmed by sequencing analysis. B: Progressive 5'-deletion analysis of the mouse nectin-2 $5^{\prime}$ flanking region was performed between $n t-946$ and +34 by direct PCR amplification of the corresponding regions, followed by subsequent cloning of the amplified fragments into the promoterless pGL-3

the functional significance of these motifs in regulating nectin-2 gene transcription in the testicular cells, sitedirected mutants were constructed and transiently transfected into TM4 and GC-2spd(ts) cells, respectively (Fig. 2B). Single mutation of either dSp1, AP-1, and AP2 motifs had no significant effect on the promoter activities of TM4 and GC-2spd(ts) cells (mutants A, D, and $\mathrm{E}$ vs. wild type), whilst mutation of the pSp1 motif caused a $24.8 \%$ and a $32.5 \%$ reduction of promoter activities in TM4 and GC-2spd(ts) cells (mutant B vs. wild type), respectively. Mutation of the CRE motif also significantly reduced the promoter activities in the TM4 (50.6\% reduction) and $\mathrm{GC}-2 \mathrm{spd}(\mathrm{ts})$ cells $(44.8 \%$ reduction) (mutant C vs. wild type). These results showed that mutation of either one of these motifs (pSp1 and CRE) could only partially abolish the promoter activity.

To examine whether there is any functional cooperation among these cis-acting elements, constructs containing double or triple mutation were analyzed in TM4 and GC-2spd(ts) cells. As depicted in Figure 2B, no significant further change was observed in TM4 and GC$2 \mathrm{spd}(\mathrm{ts})$ cells when two of the elements $(\mathrm{dSp} 1+\mathrm{pSp} 1$, $\mathrm{dSp} 1+\mathrm{CRE}$, and AP-1 + CRE) were mutated concurrently (mutants $\mathrm{F}, \mathrm{G}$, and $\mathrm{J}$ vs. mutants $\mathrm{B}$ and $\mathrm{C}$ ). However, a significant increase was observed in GC-
Basic vector. Various nectin-2 promoter-luciferase constructs were cotransfected with the pSV- $\beta$-gal vector. The promoter activity of each construct was normalized by $\beta$-galactosidase activity from pSV- $\beta$-gal plasmid. The relative promoter activity was represented as the fold induction when compared to the promoterless pGL-3 Basic vector. Values represent the mean $\pm \mathrm{SD}$ of three independent experiments each performed in duplicate. a, $P<0.01$ versus pGL-3 Basic; $b$, not significant versus pGL-3 Basic.

2 spd(ts) cells, but not in TM4 cells, when double mutations of $\mathrm{pSp} 1$ and CRE motifs were performed compared with the corresponding $\mathrm{pSp} 1$ or CRE single mutation (mutant $\mathrm{H}$ vs. mutants $\mathrm{B}, \mathrm{C}$ ). A significant reduction (almost $70 \%$ reduction in both cell lines) was observed when triple mutation (dSp1, pSp1, and CRE motifs) was performed (mutant I vs. mutants $\mathrm{F}-\mathrm{H}$ and wild type), indicating that these three regulatory motifs functionally co-operate with one another to stimulate the basal nectin-2 gene transcription.

\section{Analysis of DNA-protein interactions of the dSp1 and pSp1 motifs by EMSAs}

Results from site-directed mutagenesis suggest that the three motifs (dSp1, pSp1, and CRE) within the region between $n t-316$ and -212 are required for the basal promoter activity of nectin- 2 gene, we sought to examine and identify the transcription factors from these two cell lines that bound to these three motifs. EMSAs showed that DNA-protein complexes were formed in a dose-dependent manner with synthetic oligonucleotides containing either dSp1 or pSp1 motifs when nuclear extracts from TM4 and GC-2spd(ts) cells were used (Fig. 3A,C and 4A,C). As depicted in Figure 3A,C, three DNA-protein complexes (complexes 
A

-316 GGACGCGGGATGGGCGGGGTCTTAGCCCTGAGAGG

dSp1

-281 GGCGGAGCCTGAGCCCTAGGATCGGCTTGGCGAAG

-246 A $\frac{\text { AGGGCGGGGCCTGTGACGTCATGAGTCCGGCCCG }}{\text { pSp1 }}$

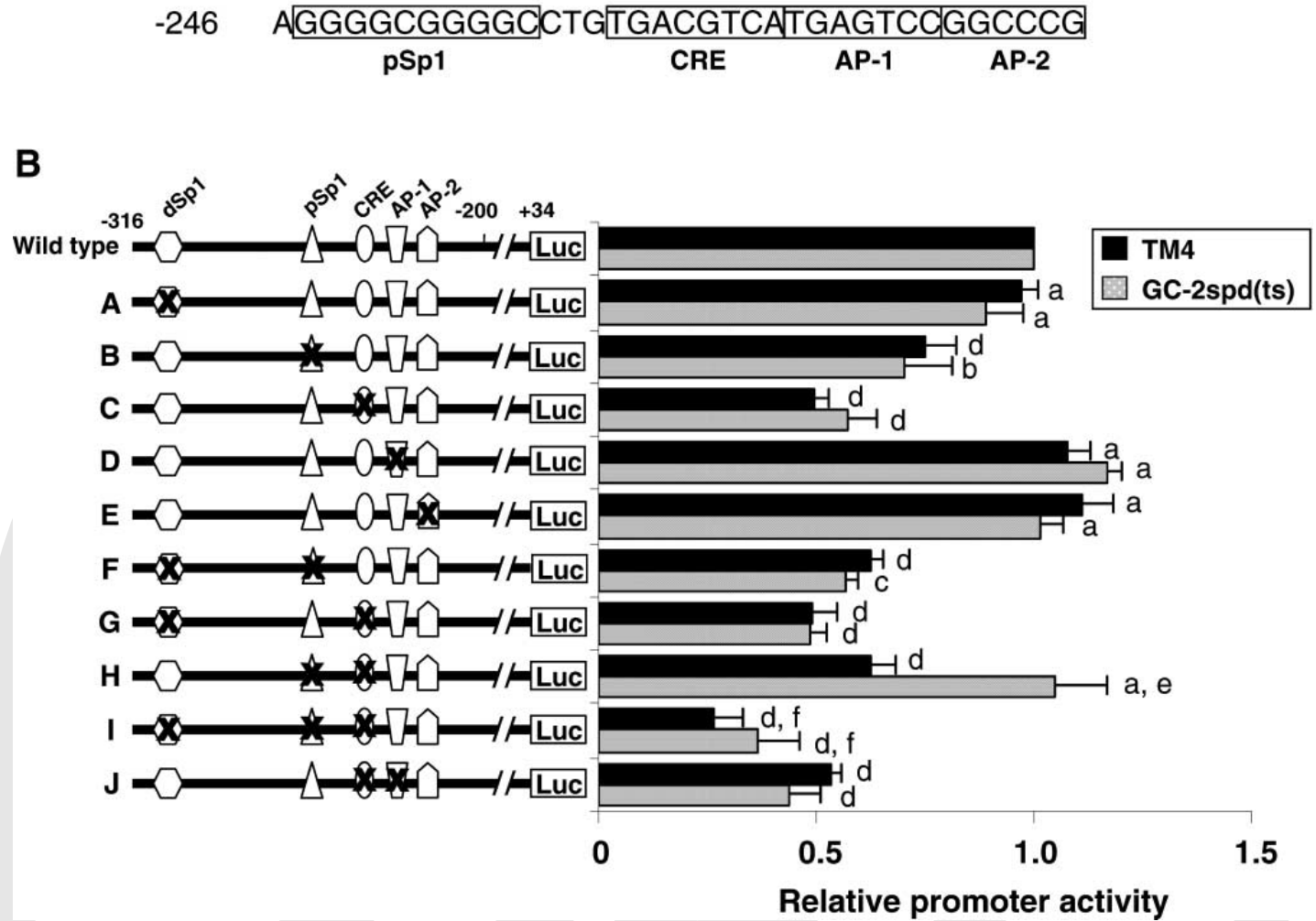

Fig. 2. A-B: Mutational analysis of the putative Sp1, CRE, AP-1, and AP-2 motifs on transcriptional activity of nectin- $25^{\prime}$-flanking region. A: Two putative Sp1, namely dSp1 and pSp1, and one each of the motifs including CRE, AP-1, and AP-2 are boxed and numbers on the left side refer to the position of nectin- 2 gene relative to the translation start site. B: A diagrammatic representation of the mutated promoter constructs (mutants A-J) is shown on the left side of the figure. Mutants were constructed by a three-step PCR mutagenesis method. Mutations are marked with black crosses. Wild type $[\mathrm{p}(-316 /+34) \mathrm{Luc}]$ or mutated nectin-2 promoter-luciferase

A-C) were observed in TM4 cells, whereas four DNAprotein complexes (complexes D-G) were formed in GC2spd(ts) cells when using double-stranded oligonucleotide containing dSp1 motif. Formation of the complexes was inhibited dose-dependently by the addition of cold dSp1 competitors (100- to 500-fold excess) (Fig. 3B,D, lanes 2-4), whilst addition of mutated dSp1 sequence failed to inhibit complex formation (Fig. 3B,D, lanes 5 and 6) in both cell types. No specific DNA-protein complex was formed when mutated labeled probe or no nuclear extract was used (Fig. 3D, lanes 7 and 13). Antibody supershifting assays showed that Sp1 was present in complexes $\mathrm{A}-\mathrm{E}$ whilst Sp3 was in complexes $\mathrm{B}, \mathrm{C}$ and $\mathrm{D}-\mathrm{F}$ since incubation of nuclear extracts from TM4 and GC-2spd(ts) cells with anti-Sp1 and anti-Sp3 antibodies abolished the formation of those complexes (Fig. 3B, lanes 7-9; Fig. 3D, lanes 8-11). Supershifted bands were observed in TM4 cells, but not in GC$2 \mathrm{spd}(\mathrm{ts})$ cells when nuclear extracts were incubated with anti-Sp1 and anti-Sp3 antibodies (Fig. 3B, lanes 7-9, arrow, vs. Fig. 3D, lanes 8-11). The absence of supershifted bands in GC-2spd(ts) cells is possibly due to construct was transiently co-transfected with the pSV- $\beta$-gal plasmid into TM4 and GC-2spd(ts) cells, respectively. The promoter activity of each construct was normalized by $\beta$-galactosidase activity. The relative promoter activity was represented as the fold induction when compared to the construct $\mathrm{p}(-316 /+34)$ Luc that was set as 1 . Values represent the mean $\pm \mathrm{SD}$ of three independent experiments each performed in duplicate. a, not significant versus wild type; $\mathrm{b}, P<0.05$ vresus wild type; c, $P<0.01$ versus wild type; d, $P<0.001$ versus wild type; e, $P<0.01$ versus mutants $\mathrm{B}$ and $\mathrm{C}$ in same cell type; $\mathrm{f}, P<0.05$ versus mutants F, G, and $\mathrm{H}$ in same cell type.

the larger size of the DNA-protein complex, making it difficult to get into the gel. Rabbit serum was used in control experiments to determine the specificity of protein-protein interaction (Fig. 3B, lane 10; Fig. 3D, lane 12). The identity of complex G in GC-2spd(ts) cells remains to be determined since antibody targeted against the Sp1 family transcription factors (Sp1 and Sp3) did not affect the formation of complex G.

When using oligonucleotide containing pSp1 motif, two DNA-protein complexes and three DNA-protein complexes were formed in TM4 and GC-2spd(ts) cells in a dose-dependent manner, respectively (Fig. 4A, complexes $\mathrm{H}$ and I; Fig. 4C, complexes J-L). Specific competition with unlabeled pSp1 probes (100- to 500fold excess) abolished the formation of complexes $\mathrm{H}-\mathrm{L}$ (Fig. 4B,D, lanes 2-4), whilst addition of unlabeled mutated pSp1 probe was unable to abolish the complex formation (Fig. 4B,D, lanes 5 and 6) in both cell lines. When mutated labeled probe or no nuclear extract was used, no DNA-protein complex was formed (Fig. 4B, lane 7 and 12; Fig. 4D, lane 7). Antibody supershift assays showed that the formation of complexes $\mathrm{H}$, J, and 

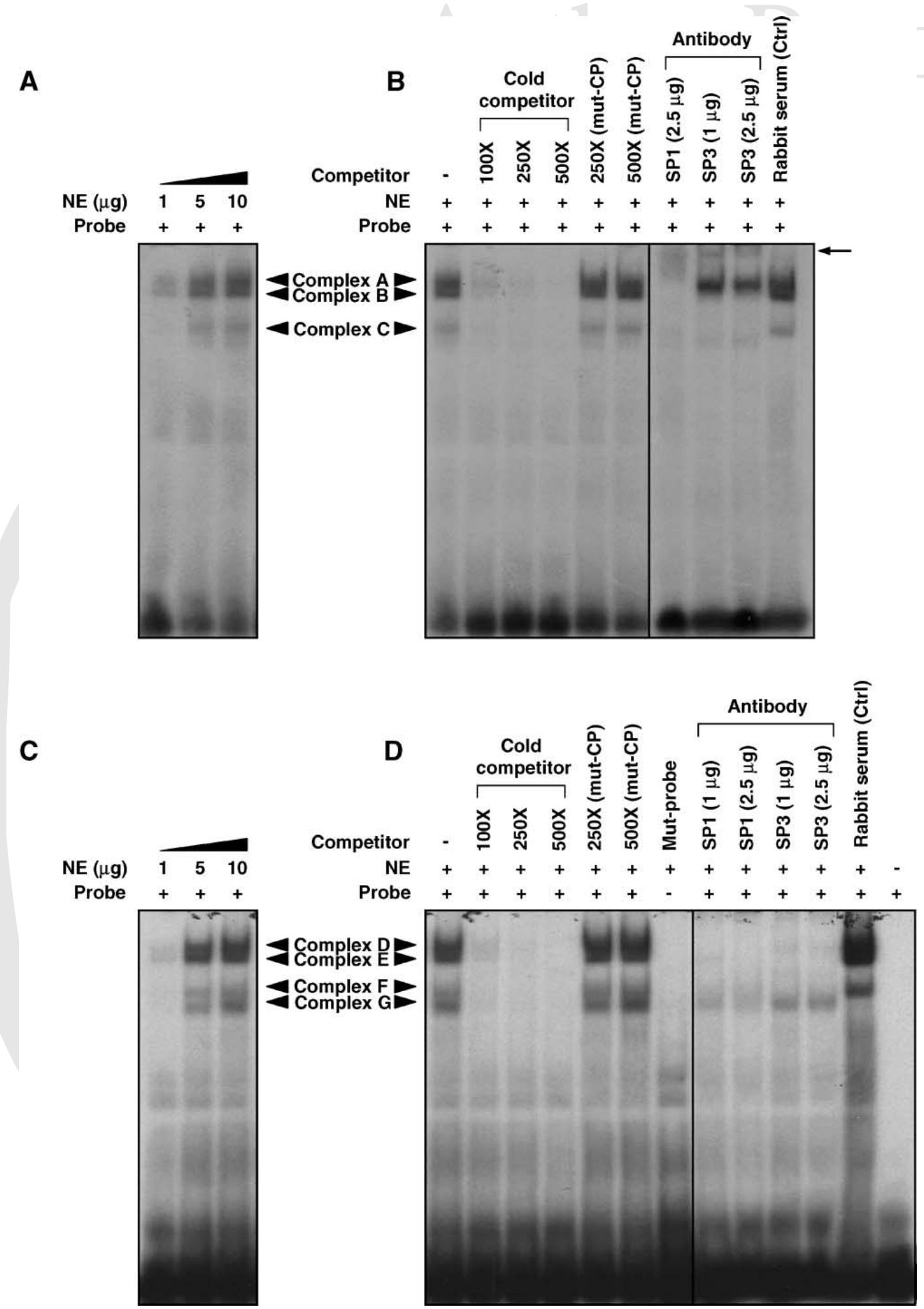

Fig. 3. A-D: EMSAs of the dSp1 motif using nuclear extracts from mouse TM4 and GC-2spd(ts) cells. Synthetic oligonucleotides containing the dSP1 sequence were annealed to form double strand DNA, end-labeled with ${ }^{32} \mathrm{P}$ and incubated with nuclear extracts from TM4 and GC-2spd(ts) cells. Formation of DNA-protein complexes (complexes A-G, arrowheads) with increasing amount (1-10 $\mu \mathrm{g})$ of TM4 (A) and GC-2spd(ts) (C) nuclear extracts. Nuclear extracts from TM4 (B) and GC-2spd(ts) (D) cells $(10 \mu \mathrm{g})$ were incubated with the radiolabeled probe $(\sim 50 \mathrm{fmol})$ in the presence of an increasing amount of a cold competitor (100- to 500-fold excess, lanes 2-4) or competitor containing the corresponding mutated sequence (250- and 500-fold excess, lanes 5 and 6). Mutated labeled probe was also incubated with the nuclear extracts as a control (D, lane 7). Nuclear extracts $(10 \mu \mathrm{g})$ from TM4 (B, lanes 7-10) and GC-2spd(ts) (D, lanes 8-12) cells were pre-incubated with anti-Sp1, anti-Sp3 antibody, or rabbit serum before addition of the radiolabeled probes. The arrow represents the supershifted bands. 


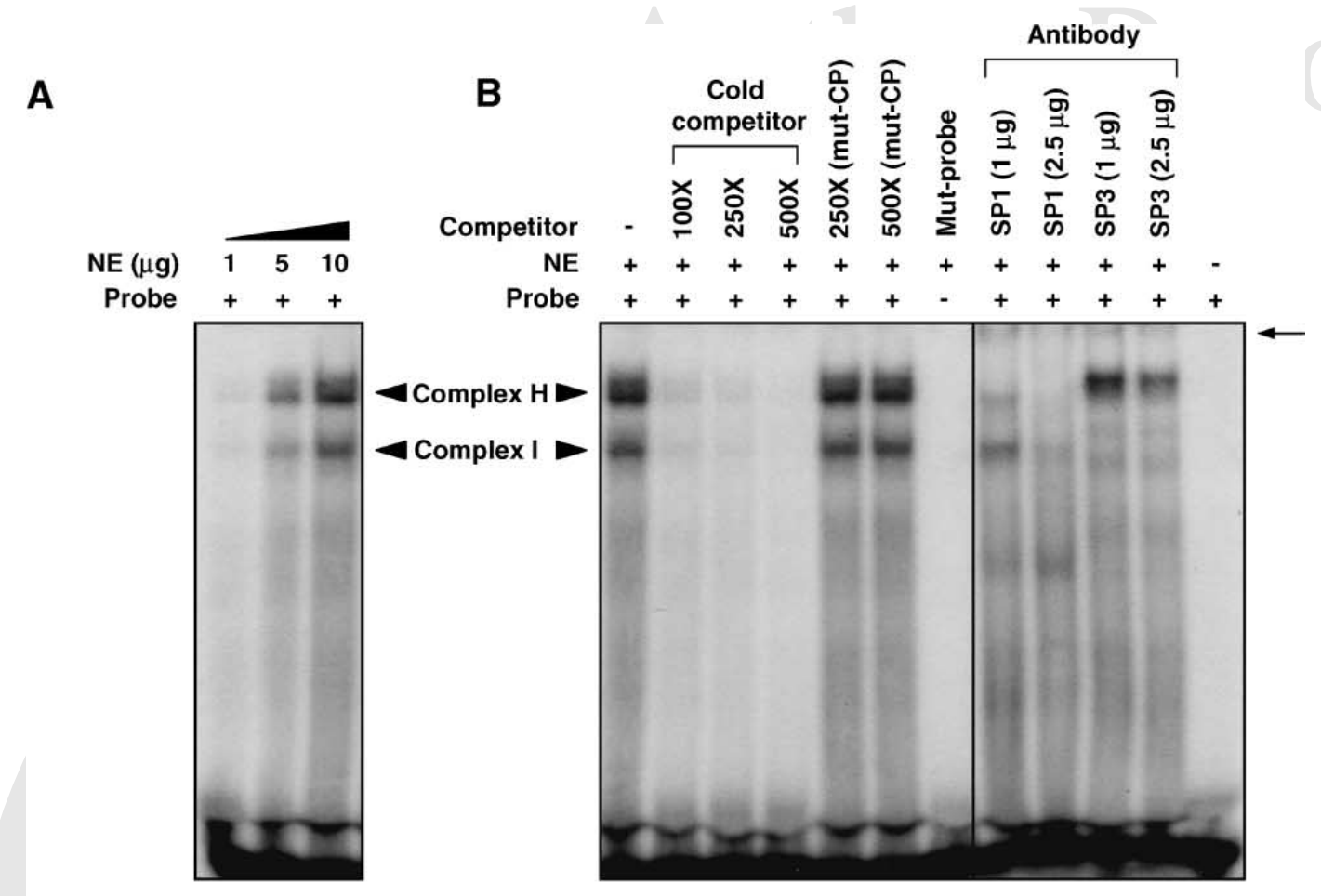

C

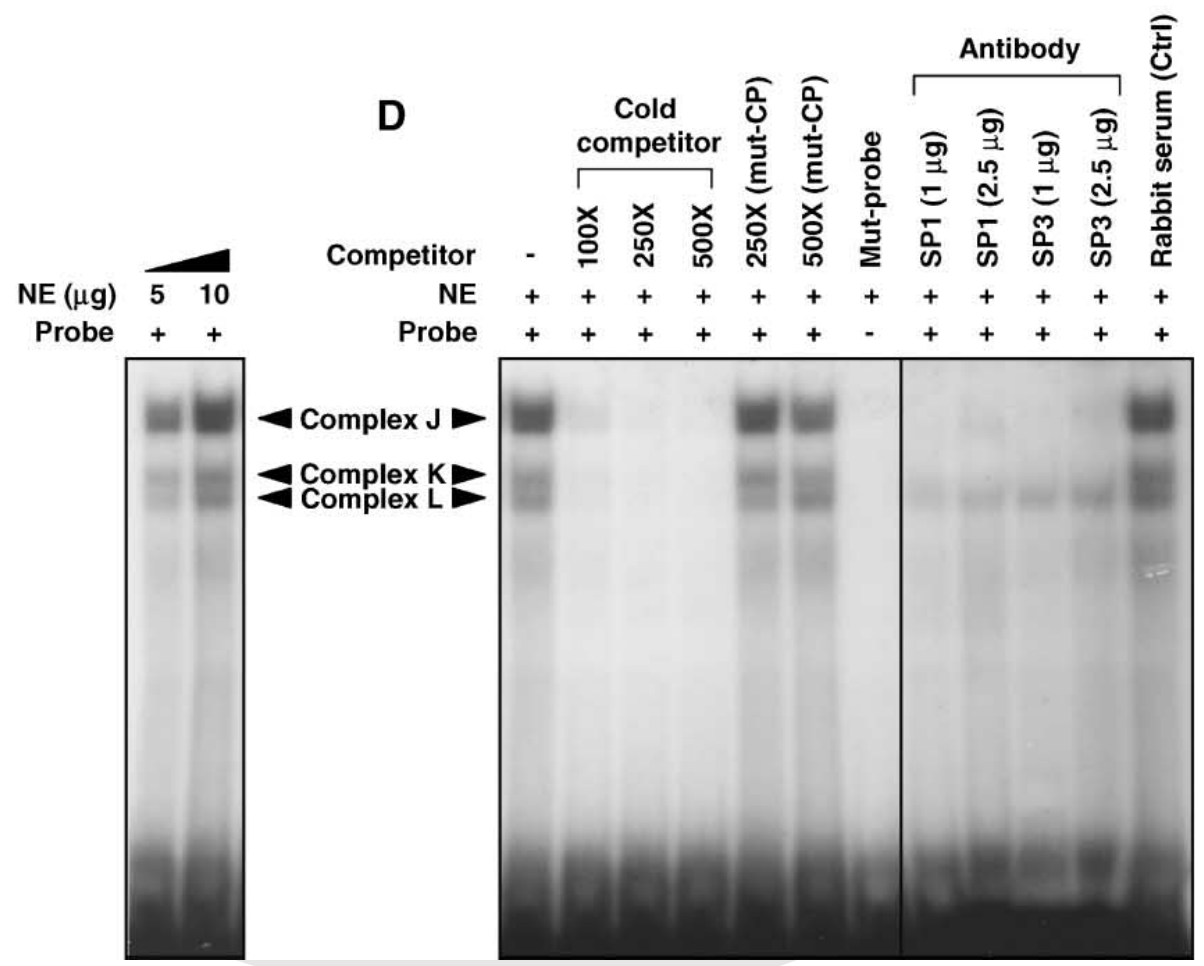

Fig. 4. A-D: EMSAs of the pSp1 motif using nuclear extracts from mouse TM4 and GC-2spd(ts) cells. Synthetic oligonucleotides containing the pSP1 sequence were annealed to form double strand DNA and end-labeled with ${ }^{32} \mathrm{P}$ and incubated with nuclear extracts from TM4 and GC-2spd(ts) cells. Formation of DNA-protein complexes (complexes $\mathrm{H}-\mathrm{L}$, arrowheads) with increasing amount (1-10 $\mu \mathrm{g})$ of TM4 (A) and GC-2spd(ts) (C) nuclear extracts. Nuclear extracts from TM4 (B) and GC-2spd(ts) (D) cells $(10 \mu \mathrm{g})$ were incubated with the radiolabeled probe $(\sim 50 \mathrm{fmol})$ in the presence of an increasing amount

$\mathrm{K}$ was abolished in the presence of anti-Sp1 antibody (Fig. 4B,D, lanes 8 and 9), whilst the antibody against Sp3 inhibited the formation of complexes I, J, and K (Fig. 4B,D, lanes 10 and 11). Supershifted bands were of a cold competitor (100- to 500-fold excess, lanes 2-4) or competitor containing the corresponding mutated sequence (250- and 500 -fold excess, lanes 5 and 6). Mutated labeled probe was also incubated with the nuclear extracts as a control (lane 7). Nuclear extracts $(10 \mu \mathrm{g})$ from TM4 (B, lanes 8-11) and GC-2spd(ts) cells (D, lanes 8-12) cells were pre-incubated with either anti-Sp1, anti-Sp3 antibody, or rabbit serum before addition of the radiolabeled probes. The arrow represents the supershifted bands.

observed in TM4 cells when nuclear extracts were incubated with either anti-Sp1 or anti-Sp3 antibodies (Fig. 4B, lanes 8-11, arrow). Rabbit serum was used to determine the specificity of protein-protein interaction 
(Fig. 4D, lane 12). The identity of complex L in GC2spd(ts) cells remains to be determined since antibody targeted against the Sp1 family transcription factors did not affect the formation of complex L.

Taken together, these results confirmed that interactions of Sp1 and Sp3 transcription factors over the dSp1 and $\mathrm{pSp} 1$ motifs were responsible for the formation of those complexes in both cell lines except complexes G (dSp1 motif) and L (pSp1 motif) found in GC-2spd(ts) cells. Presence of unidentified transcription factors in complexes $\mathrm{G}$ and $\mathrm{L}$ suggests that the transcriptional machinery of nectin-2 gene in TM4 and GC-2spd(ts) cells might not be exactly the same.

\section{Effects of overexpression of Sp1 and Sp3 on mouse nectin-2 promoter activity}

To ascertain the functional significance of $\mathrm{Sp} 1$ and Sp3 in regulating nectin-2 gene transcription, expression plasmids encoding wild type $\mathrm{Sp} 1$ and $\mathrm{Sp} 3$ were co-transfected with $\mathrm{p}(-316 /+34) \mathrm{Luc}$ in TM4 and GC$2 \mathrm{spd}(\mathrm{ts})$ cells. As shown in Figure 5A, overexpression of Sp1 upregulated the nectin-2 promoter activities in TM4 with an 1.5-fold induction when $1.5 \mu \mathrm{g}$ of $\mathrm{Sp} 1$ expression plasmids was used, although this induction was apparently not so significant in the case of GC-2spd(ts) cells. When the $p(-316 /+34)$ Luc construct was co-transfected

A

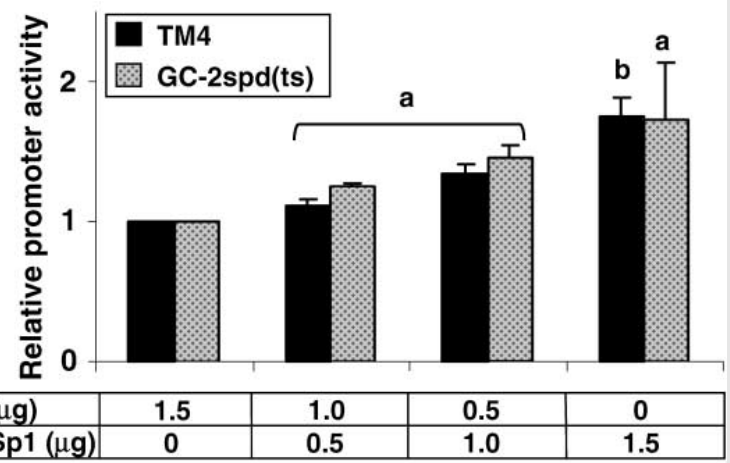

B

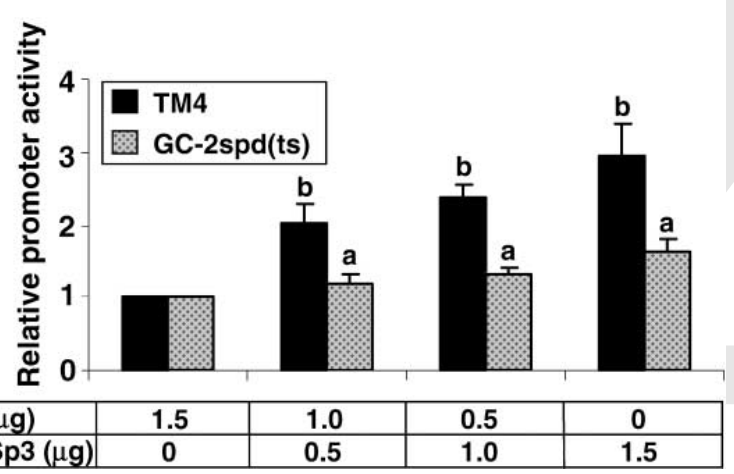

Fig. 5. A-B. Effects of overexpression of Sp1 and Sp3 on regulating the nectin-2 promoter activity in TM4 and GC-2spd(ts) cells. The construct $\mathrm{p}(-316 /+34)$ Luc was co-transfected with an increasing amount $(0-1.5 \mu \mathrm{g})$ of pCMV-Sp1 expression vector (A) or pCMV-Sp3 expression vector (B) into TM4 (solid) and GC-2spd(ts) (hatched) cells. The pCMV vectors were added to ensure that equal amounts of plasmids were used for transfection. The relative promoter activity was represented as the fold induction when compared to the control (pCMV vector) after normalized by $\beta$-galactosidase activity. Values represent the mean $\pm \mathrm{SD}$ of three independent experiments each performed in duplicate. a, not significant versus pCMV alone; b, $P<0.01$ versus pCMV alone. with Sp3 expression vector, a dose-dependent increase in promoter activity was observed in TM4 cells (Fig. 5B). However, no regulatory effect from forced expression of Sp3 was detected in GC-2spd(ts) cells (Fig. 5B), indicating that although Sp1 and Sp3 are capable to bind dSp1 and pSp1 motifs in both cell lines, Sp1 and Sp3 might exert their regulatory effect on nectin-2 promoter in a cell type-specific manner.

\section{Analysis of DNA-protein interactions of the CRE motif by EMSAs}

One DNA-protein complex (complexes $\mathrm{M}$ and $\mathrm{N}$ ) was formed in TM4 and GC-2spd(ts) cells, respectively with the synthetic oligonucleotide containing the CRE motif (Fig. 6A,C). Formation of the complex was abolished dose-dependently in the presence of increasing foldexcess of unlabeled oligonucleotide (Fig. 6B,D, lanes 24), whereas addition of mutated CRE sequence failed to inhibit the formation of the complex (Fig. 6B,D, lanes 5 and 6). No DNA-protein complex was observed when mutated labeled probe or no nuclear extract was used (Fig. 6B, lanes 7 and 11; Fig. 6D, lane 7). To get insights into the nature of nuclear protein bound to the CRE motif, antibody supershift assay was performed. A slight supershifted band was observed in TM4 and GC2 spd(ts) cells when nuclear extracts were incubated with anti-CREB antibody $(2.5 \mu \mathrm{g})$ (Fig. 6B, lane 9; Fig. $6 \mathrm{D}$, lane 10, arrow), but not with rabbit serum (Fig. 6B, lane 10; Fig. 6D, lane 11). Addition of antiCREB antibody influenced partially the formation of DNA-protein complex, suggesting that unidentified transcription factors other than CREB bind to the CRE motif.

\section{CREB and mCREB (mutated at Ser133), but not \\ KCREB and PKA, activate nectin-2 promoter activity in both cell lines}

To confirm the involvement of CREB in controlling the mouse nectin-2 promoter activity, the pCMV-CREB expression vector was co-transfected with the $\mathrm{p}(-316 /$ +34 Luc construct. As shown in Figure 7A, there were 34- and 13-fold increases in promoter activities in TM4 and GC-2spd(ts) cells, respectively, which confirms that CREB is one of transcription factors involved in the nectin-2 gene transcription. It is well-documented that the phosphorylation of Ser133 in CREB is crucial for protein kinase A (PKA)-mediated gene activation (Lalli and Sassone-Corsi, 1994). It is of interest to investigate whether the nectin-2 gene transcription requires the activation of PKA signaling pathway. Construct having CREB mutated at serine 133 (mCREB) was cotransfected with the $\mathrm{p}(-316 /+34) \mathrm{Luc}$ construct. To our surprise, significant increases (28- and 13-fold, respectively) of transcriptional activity persisted in TM4 and GC-2spd(ts) cells when the phosphorylation of CREB at serine 133 was blocked (Fig. 7A). These results suggest that the serine positioned at 133 in CREB is not the crucial phosphorylation site in the activation of nectin-2 gene transcription and the activation of nectin-2 transcription is PKA-independent. A dominant-negative mutant (KCREB) having mutations in its DNAbinding domain was co-transfected with the $\mathrm{p}(-316 /$ $+34)$ Luc construct, promoter activity was similar to the control (pCMV vector alone) observed in both cell lines when KCREB formed inactive dimers with endogenous CREB. These results suggest that transcription factor(s), other than CREB, might be able to bind CRE motif and exert its effect without the presence of CREB homodimer. 

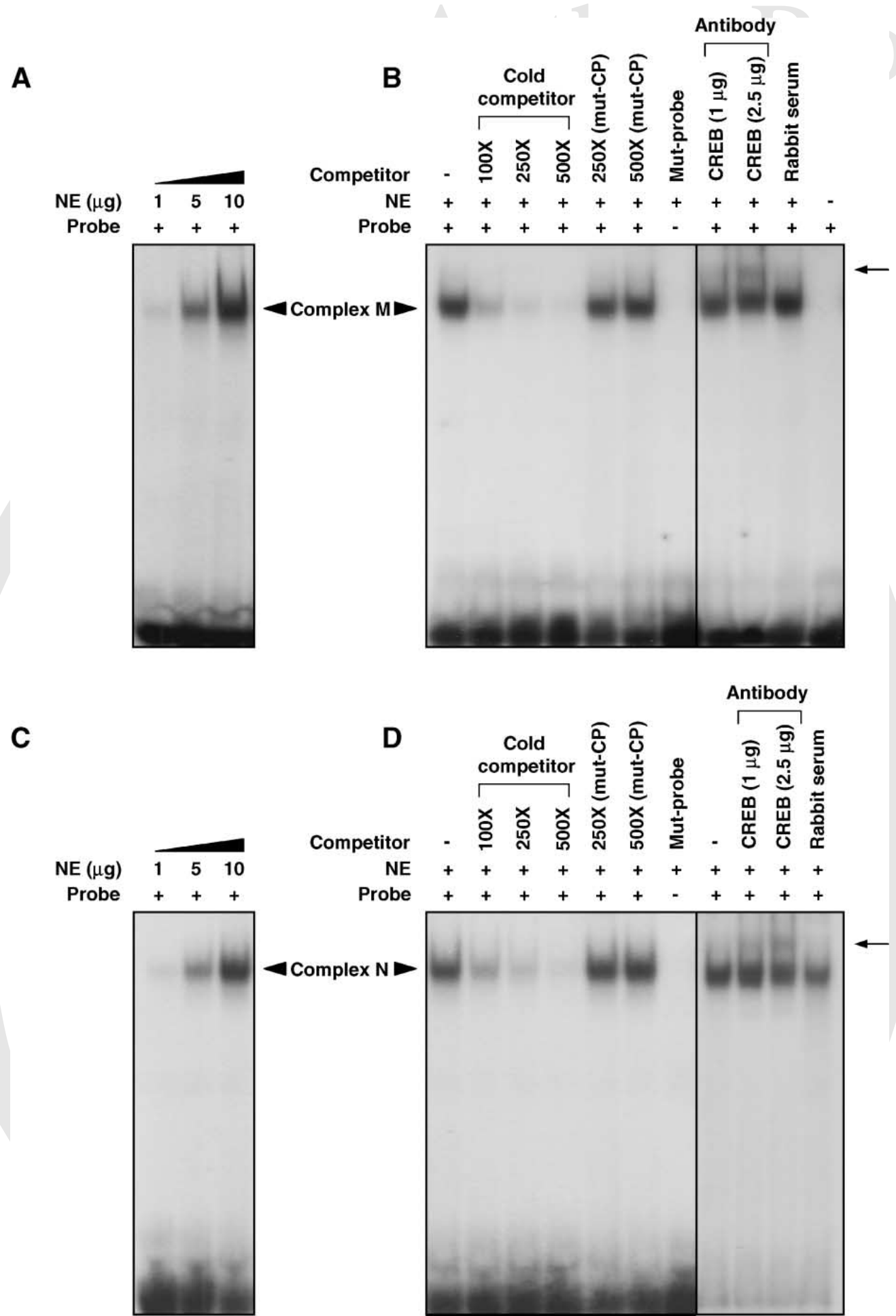

Fig. 6. A-D: EMSAs to characterize the CRE motif using nuclear extracts from TM4 and GC-2spd(ts) cells. Synthetic oligonucleotides containing the CRE motif were annealed to form double-stranded DNA and end-labeled with ${ }^{32} \mathrm{P}$. The labeled probe were incubated with an increasing amount of nuclear extracts $(1-10 \mu \mathrm{g})$ derived from TM4 (A) and GC-2spd(ts) (C) cells to allow the formation of DNA-protein complex. Nuclear extracts $(10 \mu \mathrm{g})$ from TM4 (B) and GC-2spd(ts) (D) cells were incubated with the radiolabeled CRE probe in the presence of an increasing amount of cold competitor (100- to 500-fold excess,

Overexpression of mCREB was unable to inhibit the nectin-2 promoter activity, suggesting that the activation of nectin-2 gene transcription is in a PKA-independent manner. To investigate whether nectin-2 gene transcription requires the activation of PKA signaling lanes 2-4) or mutated cold competitor (250- and 500-fold excess, lanes $5-6$ ). No DNA-protein complex was formed when mutated labeled probe (B and D, lane 7) was used. Supershift analyses were performed by pre-incubation of anti-CREB antibody or rabbit serum with TM4 $(B$, lanes 8-10) and GC-2spd(ts) (D, lanes 9-11) nuclear extracts (10 $\mu \mathrm{g})$ before the addition of the labeled CRE probe. Specific DNAprotein complexes are indicated with black arrowheads (complexes M and N) and the arrows represents the supershifted bands.

pathway, we tested the effect of PKA overexpression, forskolin (adenylate cyclase activator), and H-89 (protein kinase A inhibitor) on nectin-2 promoter activities of two cell lines. Cells co-transfected with $p(-316 /$ $+34)$ Luc construct and pCMV-PKA vector showed no 


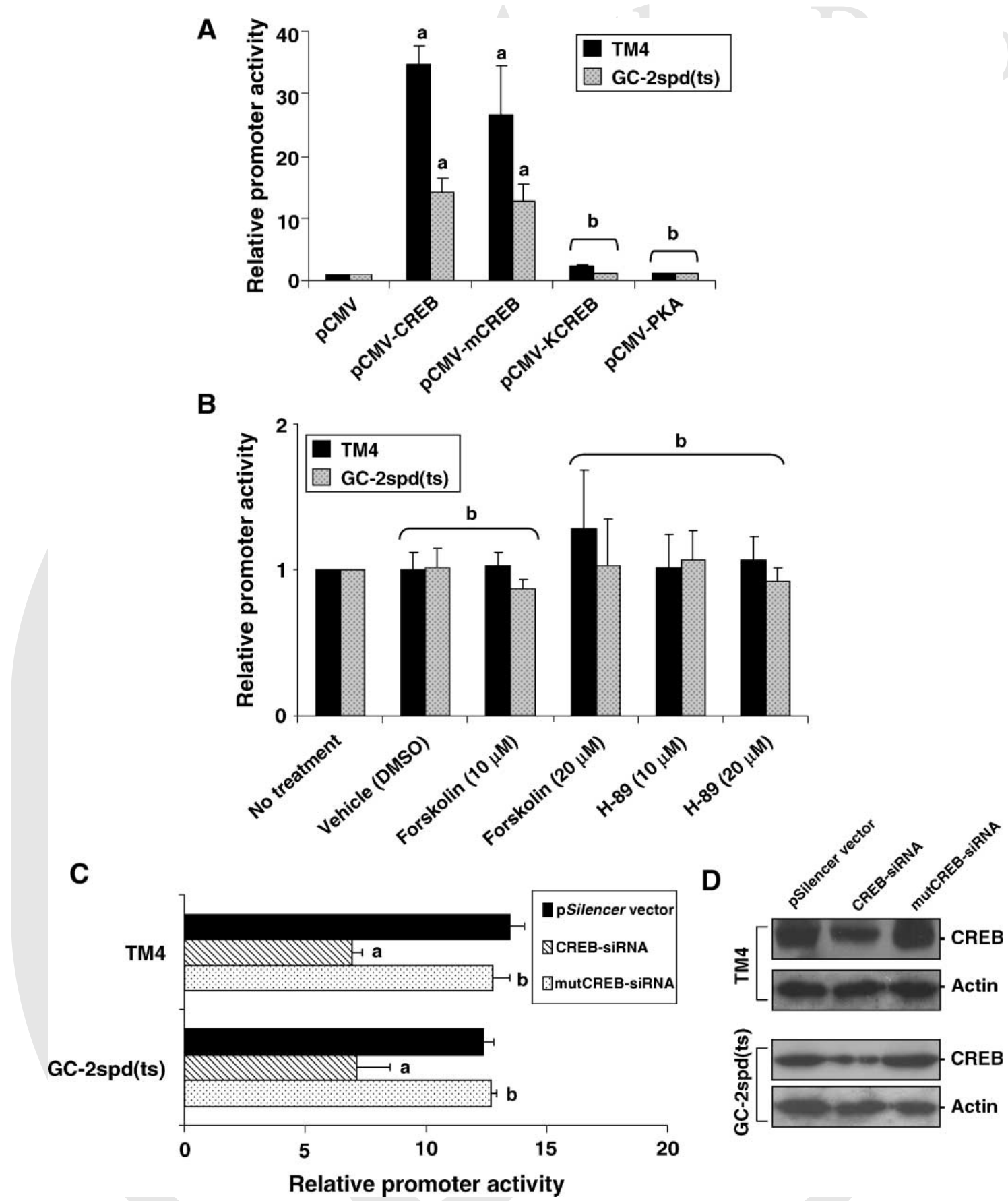

Fig. 7. A-D: Effects of CREB, mCREB, KCREB, PKA, forskolin, $\mathrm{H}-$ 89, and CREB-siRNA on nectin-2 promoter activity in TM4 and GC2 spd(ts) cells. A: The $p(-316 /+34)$ Luc construct was co-transfected with the expression vectors (pCMV-CREB, pCMV-mCREB, pCMVKCREB, and pCMV-PKA) into TM4 and GC-2spd(ts) cells. B: Cells transfected with $p(-316 /+34)$-Luc construct were treated with different concentrations of forskolin $(10 \mu \mathrm{M}$ or $20 \mu \mathrm{M})$ or H-89 $(10 \mu \mathrm{M}$ or $20 \mu \mathrm{M})$ for $3 \mathrm{~h}$ before harvest. C: $\mathrm{p}(-316 /+34)$-Luc construct was cotransfected with pSilencer vector alone, specific CREB-siRNA, or mutant CREB-siRNA (mutCREB-siRNA) in TM4 and GC-2spd(ts).

significant change in promoter activities (Fig. 7A). Cells transfected with $\mathrm{p}(-316 /+34)$ Luc construct were incubated with either forskolin or $\mathrm{H}-89$ for $3 \mathrm{~h}$ before harvest for luciferase assay. It was found that neither forskolin nor $\mathrm{H}-89$ alter the promoter activities compared to the control (no treatment) in both cell lines (Fig. 7B). These data strengthen the notion that the basal transcription of nectin-2 gene in TM4 and GC-2spd(ts) cells do not require the activation of PKA pathway.

The promoter activity of each test group was normalized by $\beta$ galactosidase activity. The relative promoter activity is represented as the fold induction when compared to pCMV alone in (A), control group (no treatment) in (B) or pGL-3 basic vector in (C). D: Proteins were extracted from cells and probed with anti-CREB and anti-actin antibodies. Values represent the mean $\pm \mathrm{SD}$ of three independent experiments each performed in duplicate. a, $P<0.01$ versus control (pCMV alone); b, not significant versus control (pCMV alone, no treatment or pSilencer alone).

To further confirm a functional role of CREB on nectin-2 transcription, the siRNA approach was used. Co-transfection of a specific CREB-siRNA with $\mathrm{p}(-316 /$ $+34)$ Luc blunted the nectin-2 promoter activity by approximately $50 \%$ in both TM4 and GC-2spd(ts) cells, whereas a mutated version of the sequence and the pSilencer 1.0 -U6 vector alone had no effect (Fig. 7C). The CREB-siRNA reduced of about $50 \%$ the protein level, in agreement with the reduced activity of the reporter 
construct. The mutated siRNA and vector alone showed no effect (Fig. 7D). These data strongly support the notion that CREB is a major transcription regulator of nectin-2 promoter.

The basic helix-loop-helix (bHLH) transcription factor (c-Jun) binds to the putative CRE motif

Both EMSA analyses and overexpression studies demonstrated that an unknown transcription factor bound to the CRE motif was playing a crucial role in regulating nectin-2 gene transcription. To identify the proteins that participated in the above interaction, EMSA was performed in the presence of several consensus oligonucleotides including AP-1, Egr, and Smad3/4 (Fig. 8A). The formation of complexes M and N was partially abolished in the presence of AP-1 consensus oligonucleotide (250- to 500 -fold excess) in both TM4 and GC-2spd(ts) cells when compared to the control (Fig. 8B,C, lanes 2 and 3 vs. lane 1), but not inhibited by other sequences such as the Egr consensus or Smad3/4

A

\begin{tabular}{|l|l|}
\hline & Sequence $\left(\mathbf{5}^{\prime} \rightarrow \mathbf{3}^{\prime}\right)$ \\
\hline Probe (CRE motif) & GCCTGTGACGTCATGAGTCCG \\
\hline Mutated CRE Probe & GCCTGTGACGTCATtcGTtCG \\
\hline AP-1 consensus & CGCTTGATGAGTCAGCCGGAA \\
\hline Egr consensus & GGATCCAGCGGGGGCGAGCGGGGGCGA \\
\hline Smad3/4 consensus & TCGAGAGCCAGACAAAAACCAGACATT \\
\hline
\end{tabular}

B

(CRE motif) + + + + +

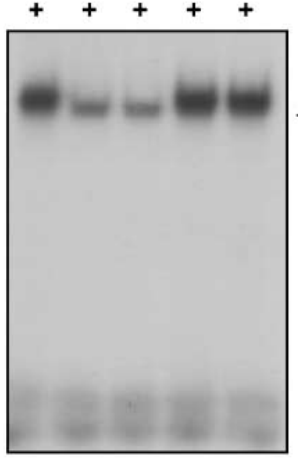

Complex M

D

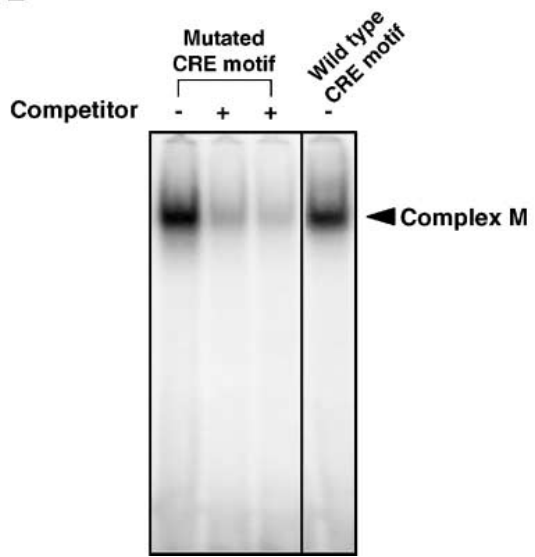

E

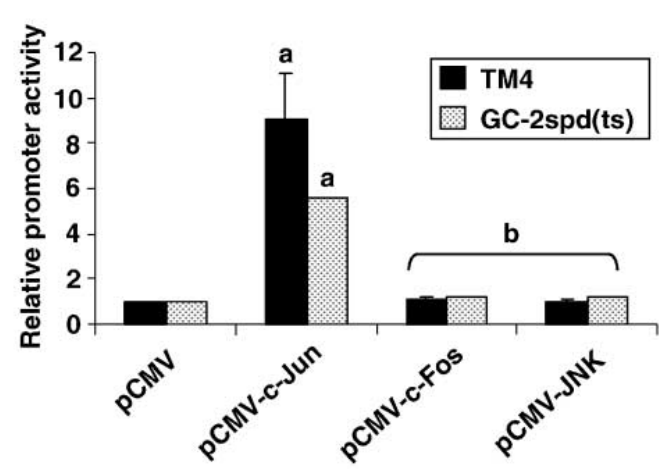

site (D, lanes $1-3$ vs. wild type probe, lane 4 ) was used in EMSA to assess the complex formation using nuclear extracts from TM4 cells. $\mathrm{E}$ : The $\mathrm{p}(-364 /+34)$ construct were co-transfected with either empty expression vector (pCMV) or expression vector encoding c-Jun, c-Fos, and JNK cDNAs. The relative promoter activity was represented as the fold induction when compare to the control (pCMV alone) after being normalized by $\beta$-galactosidase activity. Values represent the mean $\pm S D$ of three independent experiments each performed in duplicate. a, $P<0.01$ versus control; b, not significant versus control.

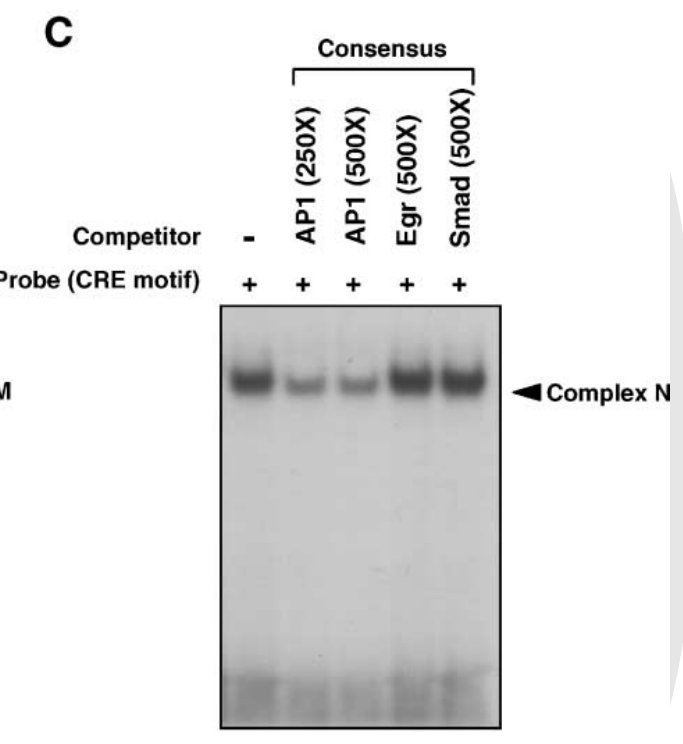
cleotides. A CRE motif having the intact CRE site and mutated AP-1

Fig. 8. A-E: Binding of AP-1 transcription factor c-Jun, but not cCRE/AP-1 motif and effects of AP-1 transcription fact (pone) and consensus AP-1, Egr, and Smad3/4 oligonucleotides in EMSAs are shown. Nuclear extracts $(10 \mu \mathrm{g})$ from TM4 (B) and GC $2 \mathrm{spd}(\mathrm{ts})(\mathrm{C})$ cells were incubated with the radiolabeled probe (CRE/ 
binding motif (500-fold excess) (Fig. 8B,C, lanes 4 and 5), suggesting specific interactions between the putative CRE motifs and AP-1 transcription factors.

To ensure that the AP-1 protein binds to the CRE motif rather than the nearby AP-1 motif, a mutated labeled probe having the intact CRE motif along with mutated AP-1 site was used in EMSA analysis. As shown in Figure 8D, the mutated labeled probe was capable to form the complex M using TM4 nuclear extract (lane 1 vs. lane 4, wild type probe). When cold competitors were added, the complex formation was inhibited dose-dependently (lanes 2 and 3). Similar result was obtained when germ cell nuclear extract was used (data not shown). These results indicate that complexes $\mathrm{M}$ and $\mathrm{N}$ were bound to the CRE motif instead of AP-1 motif.

AP-1 transcription factor consists of either Jun homodimers or Fos/Jun heterodimeric complexes. As shown in Figure 8E, co-transfection of the pCMV-c-Jun expression vector increased the promoter activity of $\mathrm{p}(-316 /+34)$ Luc construct more than eightfold and fivefold over the controls in TM4 and GC-2spd(ts) cells, respectively. No such increase was detected when pCMV-c-Fos or pCMV-JNK overexpression vector was co-transfected with $\mathrm{p}(-316 /+34)$ Luc into TM4 and GC$2 \mathrm{spd}(\mathrm{ts})$ cells. These results demonstrated that c-Jun, an AP-1 transcription factor family member, is capable to bind to the CRE motif to drive the nectin-2 transcription machinery.

\section{In vivo binding of CREB, Sp1, and c-Jun to the mouse nectin-2 promoter}

To assess the in vivo association of CREB, Sp1, and cJun with the mouse nectin-2 promoter, the ChIP assay was performed in TM4 and GC-2spd(ts) cells (Fig. 9B, upper part). Positive PCR signals were detected in both TM4 and GC-2spd(ts) using primer pair \#895/\#894 when immunocprecipitation was performed using anti-CREB (lane 2), anti-Sp1 (lane 3), anti-Sp3 (lane 4), anti-c-Jun (lane 5) antibody, but not anti-p53 antibody (lane 6), supporting the notion that these proteins including CREB, Sp1, and c-Jun interact with the nectin-2 promoter in in vivo situation. No PCR signal was observed from the negative controls including: rabbit serum (lane 7) and no template (lane 9). Negative PCR signal were obtained in both cell lines using primer pair \#1099/\#1100, which amplifies a non-specific sequence of the nectin-2 gene about one kilobase downstream from the promoter region (Fig. 9B, lower part).

\section{Changes in the steady-state mRNA levels of CREB and nectin-2 in staged seminiferous tubules}

Tubules were isolated by transillumination stereomicroscopy and divided into two groups. These included the dark zone combined with dark spot zone (stages IIVIII) and weak spot zone combined with pale zone (stages IX-I). The steady-state CREB mRNA was detected in all stages of the seminiferous tubules, yet their levels became lower in stages IX-I (Fig. 10, upper part). This pattern of CREB expression was consistent with previous studies that there is a cyclic expression of CREB in the seminiferous epithelium where high level of CREB mRNA is present in stages I-VIII of the spermatogenic cycle (Waeber et al., 1991). The steadystate nectin-2 mRNA level exhibits a similar expression pattern with a higher mRNA level at stages II-VIII (middle part). This coordinated relationship between CREB and nectin-2 supports the hypothesis that cyclic expression of CREB plays a role in controlling the timely
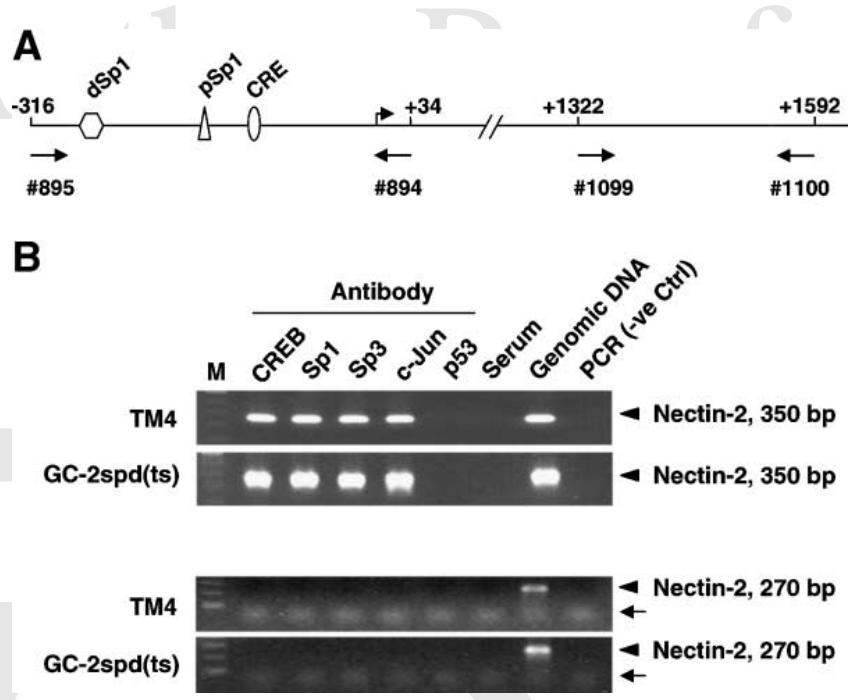

Fig. 9. A-B: Chromatin immunoprecipitation analysis for CREB, $\mathrm{Sp} 1$, and c-Jun association with mouse nectin-2 promoter. A: A diagram of the mouse nectin-2 promoter showing the two Sp1 binding sites and the CRE motif. Arrows indicate the primers used for PCR analysis and their relative location. B: Nuclear proteins from TM4 and GC2-spd(ts) cells and genomic DNA were cross-linked by formaldehyde and isolated genomic DNA was immunoprecipitated with antiCREB, anti-Sp1, anti-Sp3, anti-c-Jun, or anti-p53 antibody (lanes 26 , respectively). After immunoprecipitation, the mouse nectin-2 promoter $(-316-+34)$ was amplified by PCR using two sets of primer pairs: \#895/\#894 (upper part) and \#1099/\#1100 (lower part). PCR products were analyzed by an agarose gel. Immunoprecipitation using anti-p53 antibody or rabbit serum were carried out as negative control. Black arrows represent the primer dimmers.

expression of nectin-2 gene in the seminiferous epithelium, which in turn modulates the dynamic of cell junctions between Sertoli cells and germ cells.

\section{DISCUSSION}

In the present study, we have characterized the regulatory elements involved in the expression of mouse nectin-2 gene in two testicular cell lines, TM4 (Sertoli) and GC-2spd(ts) (germ) cells. The nectin-2 core promoter is relatively short $(\sim 100 \mathrm{bp}$ in length) and lacks canonical TATA and CAAT boxes. It contains two putative Sp1 binding sites and one each of the CRE, AP-1, and AP-2 motifs next preceding to each other.

Mutational analysis showed that single mutation of either pSp1 or CRE motifs partially abolished the promoter activity in TM4 and GC-2spd(ts) cells. Interestingly, a significant rebound in promoter activity was observed in GC-2spd(ts) cells, but not in TM4 cells when

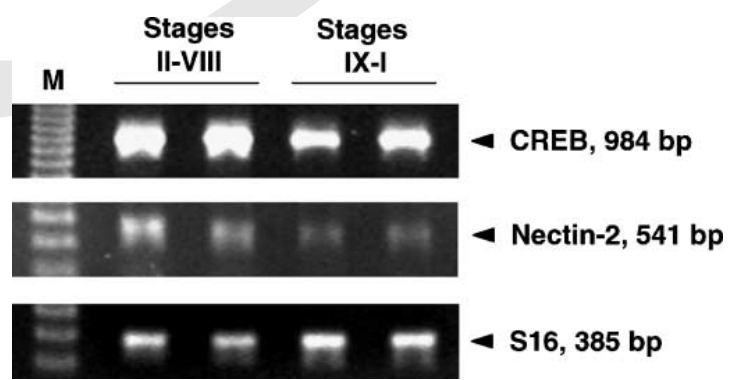

Fig. 10. Changes in the steady-state mRNA levels of CREB and nectin-2 in staged seminiferous tubules. Staged tubules were isolated by transillumination stereomicroscopy. Total RNA was extracted and RT-PCR was performed using gene-specific primers. The authenticity of the PCR product was confirmed by sequencing analysis. 
both pSp1 and CRE motifs were mutated. Since in the EMSA analysis, there was an apparent difference in the pattern of DNA-protein complex formation the pSp1 motif when nuclear extracts from TM4 and GC-2spd(ts) cells were used, an unknown trans-acting factors of the pSp1 motif in GC-2spd(ts) cells might be able to interact with the pSp1, CRE, or dSp1 motif, but with the preference of interacting with the pSp1 and CRE motifs to form a core complex. When both pSp1 and CRE motifs were mutated, this unknown nuclear factor element still exerted its positive effect via interaction with the dSp1 motif. Therefore, the promoter activity could be maintained in GC-2spd(ts) cells. When both dSp1, pSp1 and CRE motifs are concurrently mutated, this unknown factor failed to interact with either one of the motifs, which results in a significant drop in promoter activity. In addition, co-transfection of either Sp1 or Sp3 overexpression plasmids significantly increased nectin-2 promoter activity in TM4 cells, whereas overexpression of Sp1 and Sp3, exerted no significant regulatory effect on nectin-2 promoter activity in GC-2spd(ts) cells. These results from EMSAs and overexpression analyses unequivocally demonstrated that the regulatory machinery of nectin-2 gene transcription in TM4 and GC-2spd(ts) cells might not be exactly the same.

Another intriguing finding in this study is the involvement of CREB and AP-1 family proteins in the regulation of nectin-2 gene transcription. Overexpression of CREB in TM4 as well as in GC-2Spd(ts) cells exert 34- and 14-fold increase in promoter activity respectively, suggesting that CREB acts as an activator in nectin-2 gene transcription. The involvement of CREB family members in transcriptional regulation in the testis is not limited to nectin-2 gene, several genes involved in spermatogenesis such as murine spermatogenesis-associated protein-2 gene and murine sperm adhesion molecule-1 gene have been found to be regulated by CREB via the CRE motif (Zheng and Martin-Deleon, 1999; Slongo et al., 2003). Previous studies using in situ hybridization analysis has showed that Sertoli CREB mRNA is present in stages I-VIII of the spermatogenic cycle and the amount decreases to an undetectable level during stages IX-XIV (Waeber et al., 1991). The time frame of high CREB expression level at stages I-VIII coincides with the formation of nectin-2based Sertoli-spermatid AJs (for reviews, see Don and Stelzer, 2002; Ozaki-Kuroda et al., 2002). Our analysis of the staged tubules provides an additional line of evidence to show cyclic expressions of CREB and nectin2 on junction dynamics in the seminiferous epithelium. It is logical to speculate that the presence of high level of CREB at stages II-VIII might upregulate the nectin-2 gene transcription and allow the formation of nectin-2based Sertoli-spermatid AJs. At stage IX-I, spermiation takes place to allow the release of mature spermatids, which is concomitant with low level of CREB expression. It is believed that the basal nectin-2 gene transcription is greatly inhibited without the presence of CREB at these stages, resulting in the disassembly of AJs between Sertoli cells and spermatids.

Other than CREB, it has also shown that the formation of DNA-protein complexes $\mathrm{M}$ and $\mathrm{N}$ on CRE labeled probe (CRE motif + AP motif) were partially abolished in the presence of the nectin-2 AP-1 consensus oligonucleotides. These observations suggest that the member(s) of AP-1 transcription factor family is capable to interact with the CRE/AP-1 motif. The formation of complexes $\mathrm{M}$ and $\mathrm{N}$ was not affected by the use of the mutated labeled CRE probe (intact CRE motif + mutated AP motif). These results clearly demonstrate the CRE motif is the cis-acting element involved in nectin-2 gene transcription, but not the AP-1 motif. To ascertain the functional importance of the AP-1 protein to the CRE motif, overexpression of two members of AP1 protein including c-Jun and c-Fos were performed. To our surprise, a significant increase in the promoter activity in TM4 and GC-2spd(ts) cells [eightfold in TM4 and sixfold GC-2spd(ts) cells] was observed when c-Jun, but not c-Fos, was overexpressed. Studies have revealed that AP-1 proteins can form either Jun homodimers or Fos/Jun heterodimers and interact with the CRE motif to drive the promoter activity, as in the case of human neurotensin/neuromedin $\mathrm{N}$ promoter (Hai et al., 1989; Hadman et al., 1993; Chatton et al., 1995; Evers et al., 1995). Our data clearly demonstrated that induced expression of c-Fos has no apparent regulatory effect on nectin-2 promoter as heterodimers formed by exogenous c-Fos protein with endogenous Jun proteins, like c-Jun and Jun D, were unable to activate nectin-2 promoter in both cell lines. Since c-Jun is capable to form either homodimers or heterodimers with CREB (c-Jun/CREB) and exert its regulatory effect via the interaction with the CRE motif on certain promoters such as human cyclin D1 promoter (Sabbah et al., 1999), it is possible that the positive regulatory effect on nectin-2 promoter is mediated by either c-Jun homodimer or c-Jun/CREB heterodimer.

In conclusion, the mouse nectin-2 gene transcription in TM4 and GC-2spd(ts) cells required functional cooperation of multiple transcription factors including Sp1, Sp3, CREB, c-Jun, and an unknown transcription factor. Given the fact that the heterotypic intercellular junctions with Sertoli cells are downregulated when spermatids are released (Takai and Nakanishi, 2003), it is possible that the cyclic expression of CREB in seminiferous epithelium might be a crucial mechanism to regulate the assembly and disassembly of Sertolispermatid AJs via the control of nectin-2 gene transcription.

\section{ACKNOWLEDGMENTS}

We thank Dr. Lin S.C. for providing various expression vectors encoding the wild-type CREB (pCMVCREB), CREB mutated at serine 133 (pCMV-mCREB), wild-type PKA (pCMV-PKA), wild-type c-Jun (pCMV-cJun), and wild-type c-Fos (pCMV-c-Fos). We also thank Dr. Tsim K.W. for providing us the dominant-negative CREB expression vector (pCMV-KCREB). This work was supported in part by grants from the Hong Kong Research Grant Council (HKU 7194/01M, HKU 7413/ 04M and HKU7536/05M) and The University of Hong Kong (Seed Fund for the Strategic Theme on Healthy Aging to W.M.L. and CRCG Small Project Funding to W.Y.L.).

\section{LITERATURE CITED}

$\underline{\text { Aoki }}^{\mathrm{Q} 2} \mathrm{~J}$, Koike S, Asou H, Ise I, Suwa H, Tanaka T, Miyahara M, Nomoto A 1997. Mouse homolog of poliovirus receptor-related gene 2 product, mPRR2 mediates homophilic cell aggregation. Exp Cell Res 235:374-384.

Baek SJ, Horowitz JM, Eling TE. 2001. Molecular cloning and characterization of human nonsteroidal anti-inflammatory drug-activated gene promoter. Basal transcription is mediated by Sp1 and Sp3. J Biol Chem 276:33384-33392.

Bouchard MJ, Dong Y, McDermott BM, Lam DH, Brown KR, Shelanski M, Bellve AR, Racaniello VR. 2000. Defects in nuclear and cytoskeletal morphology and mitochondrial localization in spermatozoa of mice lacking nectin-2, a component of cell-cell adherens junctions. Mol Cell Biol 20:2865-2873.

Chatton B, Bahr A, Acker J, Kedinger C. 1995. Eukaryotic GST fusion vector for the study of protein-protein associations in vivo: Application to interaction of ATF $\alpha$ with Jun and Fos. Biotechniques 18:142-145.

Don J, Stelzer G. 2002. The expanding family of CREB/CREM transcription factors that are involved with spermatogenesis. Mol Cell Endocrinol 187:115124. 
Evers BM, Wang X, Zhou Z, Townsend CM, Jr., McNeil GP, Dobner PR. 1995. Characterization of promoter elements required for cell-specific expression of the neurotensin/neuromedin $\mathrm{N}$ gene in a human endocrine cell line. Mol Cell Biol 15:3870-3881.

Hadman M, Loo M, Bos TJ. 1993. In vivo viral and cellular Jun complexes exhibit differential interaction with a number of in vitro generated 'AP-1- and CREBlike' target sequences. Oncogene 8:1895-1903.

Hai TW, Liu F, Coukos WJ, Green MR. 1989. Transcription factor ATF cDNA clones: An extensive family of leucine zipper proteins able to selectively form DNA-binding heterodimers. Genes Dev 3:2083-2090.

Kemler R. 1992. Classical cadherins. Semin Cell Biol 3:149-155.

Lalli E, Sassone-Corsi P. 1994. Signal transduction and gene regulation: The nuclear response to cAMP. Mol Cell Endocrinol 269:17359-17362.

Lui WY, Lee WM. 2005. cAMP perturbs inter-Sertoli tight junction permeability barrier in vitro via its effect on proteasome-sensitive ubiquitination of occludin. J Cell Physiol 203:564-572.

Mizoguchi A, Nakagawa H, Kimura K, Matsubara K, Ozaki-Kuroda K, Katata T, Honda T, Kiyohara Y, Heo K, Higashi M, Tsutsumi K, Sonoda S, Ide C, Takai Y. 2002. Nectin: An adhesion molecule involved in formation of synapses. J Cell Biol 156:555-565.

Morrison ME, Racaniello VR. 1992. Molecular cloning and expression of a murine homolog of the human poliovirus receptor gene. J Virol 66:28072813.

Mueller HM, Rosenquist TA, Takai Y, Bronson RA, Wimmer E. 2003. Loss of nectin-2 at Sertoli-spermatid junctions leads to male infertility and correlates with severe spermatozoan head and midpiece malformation, impaired binding to the zona pellucida, and oocyte penetration. Biol Reprod 69:1330bindin

Ozaki-Kuroda K, Nakanishi H, Ohta H, Tanaka H, Kurihara H, Mueller S, Irie K, Ikeda W, Sakai T, Wimmer E, Nishimune Y, Takai Y. 2002. Nectin couples cellcell adhesion and the actin scaffold at heterotypic testicular junctions. Curr Biol 12:1145-1150.

Parvinen M, Vanha-Perttula T. 1972. Identification and enzyme quantification of the stages of the seminiferous epithelial wave in the rat. Anat Rec 174: $435-450$.

Q1: Please provide the reference in the reference list.

Q2: Please provide the citation of the reference in the text.
Reymond N, Borg JP, Lecocq E, Adelaide J, Campadelli-Fiume G, Dubreuil P, Lopez M. 2000. Human nectin3/PRR3: A novel member of the PVR/PRR/nectin family that interacts with afadin. Gene 255:347-355.

Russell L. 1977a Movement of spermatocytes from the basal to the adluminal compartment of the rat testis. Am J Anat 148:313-328.

Russell L. 1977b. Observations on rat Sertoli ectoplasmic ("junctional") specializations in their association with germ cells of the rat testis. Tissue Cell 9:475-498.

Russell LD. 1980. Sertoli-germ cell interactions: A review. Gamete Res 3:179202

Sabbah M, Courilleau D, Mester J, Redeuilh G. 1999. Estrogen induction of the cyclin D1 promoter: Involvement of a cAMP response-like element. Proc Natl Acad Sci USA 96:11217-11222.

Satoh-Horikawa K, Nakanishi H, Takahashi K, Miyahara M, Nishimura M Tachibana K, Mizoguchi A, Takai Y. 2000. Nectin-3, a new member of immunoglobulin-like cell adhesion molecules that shows homophilic and heterophilic cell-cell adhesion activities. J Biol Chem 275:10291-10299.

Slongo M, Zotti L, Onisto M. 2003. Cloning and characterization of the promoter region of human spata2 (spermatogenesis-associated protein 2) gene. Biochim Biophys Acta 1625:192-196

Takai Y, Nakanishi H. 2003. Nectin and afadin: Novel organizers of intercellular junctions. J Cell Sci 116:17-27.

Vogl AW, Pfeiffer DC, Mulholland D, Kimel G, Guttman J. 2000. Unique and multifunctional adhesion junctions in the testis: Ectoplasmic specializations. Arch Histol Cytol 63:1-15.

Waeber G, Meyer TE, LeSieur M, Hermann HL, Gerard N, Habener JF. 1991. Developmental stage-specific expression of cyclic adenosine $3^{\prime}, 5^{\prime}$-monophosphate response element-binding protein CREB during spermatogenesis involves alternative exon splicing. Mol Endocrinol 5:1418-1430.

Wong CC, Lee WM. 2002. The proximal cis-acting elements Sp1, Sp3 and E2F regulate mouse mer gene transcription in Sertoli cells. Eur J Biochem 269:3789-3800.

Zheng Y, Martin-Deleon PA. 1999. Characterization of the genomic structure of the murine Spam 1 gene and its promoter: Evidence for transcriptional regulation by a cAMP-responsive element. Mol Reprod Dev 54:8-16. 


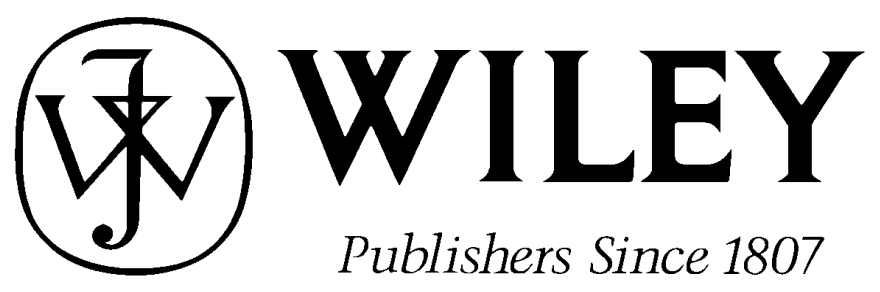

\author{
111 River Street, Hoboken, NJ 07030 \\ electronic proof checklist, Journal of Cellular Physiology

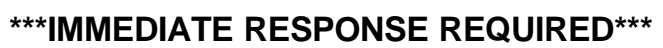 \\ Please follow these instructions to avoid delay of publication.
}

\title{
READ PROOFS CAREFULLY
}

- This will be your only chance to review these proofs.

- Please note that the volume and page numbers shown on the proofs are for position only.

ANSWER ALL QUERIES ON PROOFS (Queries for you to answer are attached as the last page of your proof.)

- Mark all corrections directly on the proofs. Note that excessive author alterations may ultimately result in delay of publication and extra costs may be charged to you.

CHECK FIGURES AND TABLES CAREFULLY (Color figures will be sent under separate cover.)

- Check size, numbering, and orientation of figures.

- All images in the PDF are downsampled (reduced to lower resolution and file size) to facilitate Internet delivery. These images will appear at higher resolution and sharpness in the printed article.

- Review figure legends to ensure that they are complete.

- Check all tables. Review layout, title, and footnotes.

\section{COMPLETE REPRINT ORDER FORM}

- Fill out the attached reprint order form. It is important to return the form even if you are not ordering reprints. You may, if you wish, pay for the reprints with a credit card. Reprints will be mailed only after your article appears in print. This is the most opportune time to order reprints. If you wait until after your article comes off press, the reprints will be considerably more expensive.

RETURN

$\square$ PROOFS

REPRINT ORDER FORM

$\square$ CTA (If you have not already signed one)

RETURN WITHIN 48 HOURS OF RECEIPT VIA FAX TO MATT HOLLENDER AT 201-748-6052

QUESTIONS?
Matt Hollender, Associate Production Editor

Phone: $201-748-5910$

E-mail:mhollend@wiley.com

Refer to journal acronym and article production number

(i.e., JCP 00-001 for Journal of Cellular Physiology ms 00-001). 
Date:

To:
Production/Contribution

ID\#

Publisher/Editorial office use only

Re: Manuscript entitled

(the "Contribution") (the "Journal")

for publication in JOURNAL OF CELLULAR PHYSIOLOGY

published by Wiley-Liss, Inc., a subsidiary of John Wiley \& Sons, Inc. ( "Wiley").

Dear Contributor(s):

Thank you for submitting your Contribution for publication. In order to expedite the publishing process and enable Wiley to disseminate your work to the fullest extent, we need to have this Copyright Transfer Agreement signed and returned to us as soon as possible. If the Contribution is not accepted for publication this Agreement shall be null and void.

\section{A. COPYRIGHT}

1. The Contributor assigns to Wiley, during the full term of copyright and any extensions or renewals of that term, all copyright in and to the Contribution, including but not limited to the right to publish, republish, transmit, sell, distribute and otherwise use the Contribution and the material contained therein in electronic and print editions of the Journal and in derivative works throughout the world, in all languages and in all media of expression now known or later developed, and to license or permit others to do so.

2. Reproduction, posting, transmission or other distribution or use of the Contribution or any material contained therein, in any medium as permitted hereunder, requires a citation to the Journal and an appropriate credit to Wiley as Publisher, suitable in form and content as follows: (Title of Article, Author, Journal Title and Volume/Issue Copyright (C) [year] Wiley-Liss, Inc. or copyright owner as specified in the Journal.)

\section{B. RETAINED RIGHTS}

Notwithstanding the above, the Contributor or, if applicable, the Contributor's Employer, retains all proprietary rights other than copyright, such as patent rights, in any process, procedure or article of manufacture described in the Contribution, and the right to make oral presentations of material from the Contribution.

\section{OTHER RIGHTS OF CONTRIBUTOR}

Wiley grants back to the Contributor the following:

1. The right to share with colleagues print or electronic "preprints" of the unpublished Contribution, in form and content as accepted by Wiley for publication in the Journal. Such preprints may be posted as electronic files on the Contributor's own website for personal or professional use, or on the Contributor's internal university or corporate networks/intranet, or secure external website at the Contributor's institution, but not for commercial sale or for any systematic external distribution by a third party (e.g., a listserve or database connected to a public access server). Prior to publication, the Contributor must include the following notice on the preprint: "This is a preprint of an article accepted for publication in [Journal title] @ copyright (year) (copyright owner as specified in the Journal)". After publication of the Contribution by Wiley, the preprint notice should be amended to read as follows: "This is a preprint of an article published in [include the complete citation information for the final version of the Contribution as published in the print edition of the Journal]", and should provide an electronic link to the Journal's WWW site, located at the following Wiley URL: http://www.interscience.Wiley.com/. The Contributor agrees not to update the preprint or replace it with the published version of the Contribution. 
2. The right, without charge, to photocopy or to transmit online or to download, print out and distribute to a colleague a copy of the published Contribution in whole or in part, for the Contributor's personal or professional use, for the advancement of scholarly or scientific research or study, or for corporate informational purposes in accordance with Paragraph D.2 below.

3. The right to republish, without charge, in print format, all or part of the material from the published Contribution in a book written or edited by the Contributor.

4. The right to use selected figures and tables, and selected text (up to 250 words, exclusive of the abstract) from the Contribution, for the Contributor's own teaching purposes, or for incorporation within another work by the Contributor that is made part of an edited work published (in print or electronic format) by a third party, or for presentation in electronic format on an internal computer network or external website of the Contributor or the Contributor's employer.

5. The right to include the Contribution in a compilation for classroom use (course packs) to be distributed to students at the Contributor's institution free of charge or to be stored in electronic format in datarooms for access by students at the Contributor's institution as part of their course work (sometimes called "electronic reserve rooms") and for inhouse training programs at the Contributor's employer.

\section{CONTRIBUTIONS OWNED BY EMPLOYER}

1. If the Contribution was written by the Contributor in the course of the Contributor's employment (as a "work-madefor-hire" in the course of employment), the Contribution is owned by the company/employer which must sign this Agreement (in addition to the Contributor's signature), in the space provided below. In such case, the company/employer hereby assigns to Wiley, during the full term of copyright, all copyright in and to the Contribution for the full term of copyright throughout the world as specified in paragraph A above.

2. In addition to the rights specified as retained in paragraph $B$ above and the rights granted back to the Contributor pursuant to paragraph $\mathrm{C}$ above, Wiley hereby grants back, without charge, to such company/employer, its subsidiaries and divisions, the right to make copies of and distribute the published Contribution internally in print format or electronically on the Company's internal network. Upon payment of the Publisher's reprint fee, the institution may distribute (but not resell) print copies of the published Contribution externally. Although copies so made shall not be available for individual re-sale, they may be included by the company/employer as part of an information package included with software or other products offered for sale or license. Posting of the published Contribution by the institution on a public access website may only be done with Wiley's written permission, and payment of any applicable fee(s).

\section{E. GOVERNMENT CONTRACTS}

In the case of a Contribution prepared under U.S. Government contract or grant, the U.S. Government may reproduce, without charge, all or portions of the Contribution and may authorize others to do so, for official U.S. Government purposes only, if the U.S. Government contract or grant so requires. (U.S. Government Employees: see note at end).

\section{F. COPYRIGHT NOTICE}

The Contributor and the company/employer agree that any and all copies of the Contribution or any part thereof distributed or posted by them in print or electronic format as permitted herein will include the notice of copyright as stipulated in the Journal and a full citation to the Journal as published by Wiley.

\section{G. CONTRIBUTOR'S REPRESENTATIONS}

The Contributor represents that the Contribution is the Contributor's original work. If the Contribution was prepared jointly, the Contributor agrees to inform the co-Contributors of the terms of this Agreement and to obtain their signature to this Agreement or their written permission to sign on their behalf. The Contribution is submitted only to this Journal and has not been published before, except for "preprints" as permitted above. (If excerpts from copyrighted works owned by third parties are included, the Contributor will obtain written permission from the copyright owners for all uses as set forth in Wiley's permissions form or in the Journal's Instructions for Contributors, and show credit to the sources in the Contribution.) The Contributor also warrants that the Contribution contains no libelous or unlawful statements, does not infringe on the rights or privacy of others, or contain material or instructions that might cause harm or injury. 


\section{CHECK ONE:}

[__ C Contributor-owned work

Contributor's signature $\quad$ Date

Type or print name and title

Co-contributor's signature

Date

Type or print name and title

ATTACH ADDITIONAL SIGNATURE PAGE AS NECESSARY

]Company/Institution-owned work (made-for-hire in the

Company or Institution (Employer-for-Hire)

Date

course of employment)

Authorized signature of Employer

Date

\section{[__ ] U.S. Government work}

\section{Note to U.S. Government Employees}

A Contribution prepared by a U.S. federal government employee as part of the employee's official duties, or which is an official U.S. Government publication is called a "U.S. Government work," and is in the public domain in the United States. In such case, the employee may cross out Paragraph A.1 but must sign and return this Agreement. If the Contribution was not prepared as part of the employee's duties or is not an official U.S. Government publication, it is not a U.S. Government work.

\section{[__ ] U.K. Government work (Crown Copyright)}

\section{Note to U.K. Government Employees}

The rights in a Contribution prepared by an employee of a U.K. government department, agency or other Crown body as part of his/her official duties, or which is an official government publication, belong to the Crown. In such case, the Publisher will forward the relevant form to the Employee for signature. 


\section{(W) WILEY \\ Journal of Cellular Physiology}

Telephone Number.

- Facsimile Number.

To: Mr. Matt Hollender

Fax: 201-748-6052

From:

Date:

Re: Journal of Cellular Physiology, ms \# 
C1

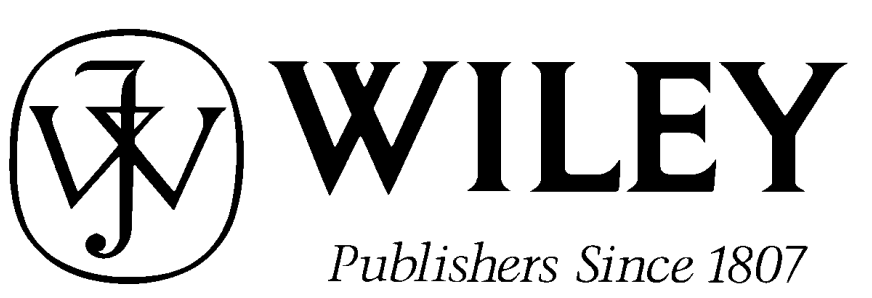

\section{REPRINT BILLING DEPARTMENT • 111 RIVER STREET ・ HOBOKEN, NJ 07030 \\ PHONE: (201) 748-6353; FAX: (201) 748-6052 \\ E-MAIL: reprints@wiley.com \\ PREPUBLICATION REPRINT ORDER FORM}

Please complete this form even if you are not ordering reprints. This form MUST be returned with your corrected proofs and original manuscript. Your reprints will be shipped approximately 4 weeks after publication. Reprints ordered after printing will be substantially more expensive.

JOURNAL JOURNAL OF CELLULAR PHYSIOLOGY

VOLUME

ISSUE TITLE OF MANUSCRIPT MS. NO. NO. OF PAGES AUTHOR(S)

\begin{tabular}{|c|c|c|c|c|c|}
\hline No. of Pages & 100 Reprints & 200 Reprints & 300 Reprints & 400 Reprints & 500 Reprints \\
\hline & $\$$ & $\$$ & $\$$ & $\$$ & $\$$ \\
\hline $1-4$ & 336 & 501 & 694 & 890 & 1052 \\
\hline $5-8$ & 469 & 703 & 987 & 1251 & 1477 \\
\hline $9-12$ & 594 & 923 & 1234 & 1565 & 1850 \\
\hline $13-16$ & 714 & 1156 & 1527 & 1901 & 2273 \\
\hline $17-20$ & 794 & 1340 & 1775 & 2212 & 2648 \\
\hline $21-24$ & 911 & 1529 & 2031 & 2536 & 3037 \\
\hline $25-28$ & 1004 & 1707 & 2267 & 2828 & 3388 \\
\hline $29-32$ & 1108 & 1894 & 2515 & 3135 & 3755 \\
\hline $33-36$ & 1219 & 2092 & 2773 & 3456 & 4143 \\
\hline $37-40$ & 1329 & 2290 & 3033 & 3776 & 4528 \\
\hline
\end{tabular}

Please send me

Please add appropriate State and Local Tax

for United States orders only.

\section{$* *$ International o
Please check one:}

If credit card order, charge to:

Credit Card No

BILL TO:

Name

Institution

Address

Purchase Order No. reprints of the above article at

(Tax Exempt

No.

Please add 5\% Postage and Handling

TOTAL AMOUNT OF ORDER**

ust be paid in currency and drawn on a U.S. bank

$\square$ Check enclosed $\square$ Bill me

$\square$ American Express $\square$ Visa Signature

Exp. Date

$\$$

$$
\$
$$

Credit Card

MasterCard

Phone

Fax

E-mail 


\section{Softproofing for advanced Adobe Acrobat Users - NOTES tool}

NOTE: ACROBAT READER FROM THE INTERNET DOES NOT CONTAIN THE NOTES TOOL USED IN THIS PROCEDURE.

Acrobat annotation tools can be very useful for indicating changes to the PDF proof of your article. By using Acrobat annotation tools, a full digital pathway can be maintained for your page proofs.

The NOTES annotation tool can be used with either Adobe Acrobat 4.0, 5.0 or 6.0. Other annotation tools are also available in Acrobat 4.0, but this instruction sheet will concentrate on how to use the NOTES tool. Acrobat Reader, the free Internet download software from Adobe, DOES NOT contain the NOTES tool. In order to softproof using the NOTES tool you must have the full software suite Adobe Acrobat 4.0, 5.0 or 6.0 installed on your computer.

\section{Steps for Softproofing using Adobe Acrobat NOTES tool:}

1. Open the PDF page proof of your article using either Adobe Acrobat 4.0, 5.0 or 6.0. Proof your article on-screen or print a copy for markup of changes.

2. Go to File/Preferences/Annotations (in Acrobat 4.0) or Document/Add a Comment (in Acrobat 6.0 and enter your name into the "default user" or "author" field. Also, set the font size at 9 or 10 point.

3. When you have decided on the corrections to your article, select the NOTES tool from the Acrobat toolbox and click in the margin next to the text to be changed.

4. Enter your corrections into the NOTES text box window. Be sure to clearly indicate where the correction is to be placed and what text it will effect. If necessary to avoid confusion, you can use your TEXT SELECTION tool to copy the text to be corrected and paste it into the NOTES text box window. At this point, you can type the corrections directly into the NOTES text box window. DO NOTcorrect the text by typing directly on the PDF page.

5. Go through your entire article using the NOTES tool as described in Step 4.

6. When you have completed the corrections to your article, go to File/Export/Annotations (in Acrobat 4.0) or Document/Add a Comment (in Acrobat 6.0).

\section{When c losing your artic le PDF be sure NOTto save changes to original file.}

8. To make changes to a NOTES file you have exported, simply re-open the original PDF proof file, go to File/Import/Notes and import the NOTES file you saved. Make changes and reexport NOTES file keeping the same file name.

9. When complete, attach your NOTES file to a reply e-mail message. Be sure to include your name, the date, and the title of the journal your article will be printed in. 